\title{
Trivium
}

Revue franco-allemande de sciences humaines et sociales - Deutsch-französische Zeitschrift für Geistesund Sozialwissenschaften

29 | 2019

Regards croisés sur le prophète de l'Islam

\section{Torah orale et hadith : transmission, interdit de l'écrit, rédaction}

\section{Gregor Schoeler}

Traducteur : Anthony Andurand

\section{(2) OpenEdition}

Journals

Édition électronique

URL : http://journals.openedition.org/trivium/6480

ISBN : 1963-1820

ISSN : 1963-1820

Éditeur

Les éditions de la Maison des sciences de l'Homme

Référence électronique

Gregor Schoeler, «Torah orale et hadith : transmission, interdit de l'écrit, rédaction », Trivium [En ligne], 29 | 2019, mis en ligne le 17 octobre 2019, consulté le 08 septembre 2020. URL : http:// journals.openedition.org/trivium/6480

Ce document a été généré automatiquement le 8 septembre 2020

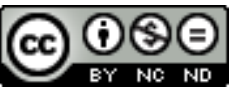

Les contenus des la revue Trivium sont mis à disposition selon les termes de la Licence Creative Commons Attribution - Pas d'Utilisation Commerciale - Pas de Modification 4.0 International. 


\title{
Torah orale et hadith : transmission, interdit de l'écrit, rédaction
}

\author{
Gregor Schoeler
}

Traduction : Anthony Andurand

\section{NOTE DE L'ÉDITEUR}

Nous remercions M. Gregor Schoeler de nous avoir accordé l'autorisation de traduire ce texte pour le présent numéro.

Wir danken Herrn Gregor Schoeler für die freundliche Genehmigung, diesen Artikel in französischer Übersetzung zu publizieren.

\section{NOTE DE L'AUTEUR}

Une première version de cet article a été présentée sous la forme d'une communication au XIV ${ }^{\mathrm{e}}$ congrès de l'Union Européenne des Arabisants et des Islamisants (Budapest, fin août - début septembre 1988). Une version retravaillée, presque trois fois plus longue, a été présentée aux participants du colloque « Hadith » qui s'est tenu à Oxford en 1988, à l'occasion duquel elle fut discutée. Sur la terminologie : Les termes common link (CL) et partial common link (PCL) sont explicités infra, au tout début des commentaires sur les diagrammes.

- « Hadith » et son synonyme « Tradition » (avec lettres majuscules) désignent l'ensemble de la Tradition, tandis que « hadith » et « tradition » (avec lettres minuscules) renvoient à une tradition particulière.

- Sur le mode de citation : le mode de citation utilisé dans les communications présentées a été repris dans le présent article (titres abrégés).

- Pour les hadiths favorables ou hostiles à la mise par écrit des traditions, l'article renvoie essentiellement à l'ouvrage Taqyìd al-'ilm (« La fixation du savoir ») d'al-Hुațìb al-Bagdādī (voir la bibliographie), la collection la plus complète de ces traditions. Le 
renvoi au passage du Taqyìd sert ainsi, dans le même temps, à désigner une tradition. D'autres références figurent dans les notes de bas de page de l'éditeur de cette œuvre, Yūsuf al-'Uš, sur les hadiths concernés. Ce n'est que dans les cas où des œuvres importantes, non utilisées par al-'Uš (le Ğāmi' de Ma'mar b. Rāšid, le Mușannaf d'Ibn Abī Šayba, etc.), apportent le hadith dont il est question qu'il est fait référence, si besoin, à ces œuvres.

\section{I.}

1 «Le Hadith entretient avec le Coran la même relation que, dans le judaïsme, l'enseignement oral vis-à-vis de l'enseignement écrit ». Cette analogie en soi évidente, telle qu'elle a été formulée par Josef Horovit $\mathrm{z}^{1}$, n'est nullement admise de manière unanime dans les études islamiques. Ignaz Goldziher ne l'a mentionnée dans son étude fondamentale «Ueber die Entwickelung des Hadïth» («Sur le développement du Hadīth $»)^{2}$ que pour la rejeter aussitôt énergiquement comme «trompeuse » et « inexacte».

2 Pour Goldziher, les nombreuses preuves fournies par Aloys Sprenger dans son étude «Ueber das Traditionswesen bei den Arabern " («Sur le système de la Tradition chez les Arabes ») du fait que des hadiths avaient déjà été fixés par écrit dans les temps les plus anciens semblaient contredire l'idée qu'aurait dominé, dans l'ancienne génération de l'Islam, l'opinion selon laquelle la mise par écrit était exclusivement réservée au Coran, le Hadith devant circuler en parallèle sous la forme d'un enseignement oral. Ces notes consistent naturellement, comme le savait déjà Sprenger ${ }^{4}$, non en « des livres au sens littéraire du terme ", mais en " des scripta, en général des notes écrites, peut-être [...] des recueils de dictons, des collections, destinés à un usage personnel $»^{5}$.

3 Goldziher reconnaissait néanmoins que la mise par écrit des hadiths, même parmi les spécialistes de la Tradition, avait des adversaires. Selon lui, cette "aversion pour l'écrit » ne domina pas dès les premiers temps, mais fut «la conséquence de préjugés qui se sont développés ultérieurement $»^{6}$. Il se forma en effet, parmi les spécialistes du hadith, une longue querelle, pour savoir s'il fallait seulement conserver les traditions au moyen de la mémoire et les transmettre oralement, ou bien si l'on pouvait aussi les mettre par écrit sans hésitation. Cette querelle fut toutefois, comme le souligne Goldziher à deux reprises, purement "théorique» et ne s'immisça pas dans la «pratique généralisée » de la mise par écrit des hadiths.

4 Goldziher n'a ainsi nullement prétendu qu'après une première période durant laquelle on aurait mis par écrit des hadiths sans réserve, des intérêts théologiques et des préoccupations religieuses seraient apparus, qui auraient provoqué une aversion à l'égard de l'écrit et l'arrêt de sa diffusion (comme on peut le lire dans un ouvrage de référence, qui souhaite dissiper une "superstition » - à savoir celle du caractère oral qu'aurait longtemps revêtu la transmission du Hadith -, mais qui a fait naître à son tour une autre "superstition", à travers la restitution déformée qu'il propose des conceptions de Goldziher ${ }^{7}$ ).

5 Toutefois, dans son rejet de l'analogie en question, Goldziher était parti du principe que l'enseignement oral des juifs - c'est-à-dire le contenu du Talmud (Mishna et Gémara) et le Midrash (l'exégèse de textes bibliques) formant avec lui une unité ${ }^{8}-$, qui existe aujourd'hui sous une forme écrite et imprimée, tout comme l'enseignement écrit - le 
Pentateuque ou la Bible -, avait été effectivement transmis à l'origine, durant des siècles, de manière purement orale. En revanche, on sait aujourd'hui qu'il n'en fut pas ainsi. On a pu réunir de nombreux témoignages de l'utilisation de notes écrites'. Il n'y eut jamais d'interdit formellement promulgué et universellement reconnu. Toutefois, «il est vrai qu'une forte opposition à l'écrit s'est fréquemment élevée, en particulier contre l'écriture des halakhōth (règles en matière de prescriptions religieuses) ». Cette désapprobation, cependant, vise moins l'écrit en soi, que « l'écrit à des fins d'utilisation publique $»^{10}$. De ce point de vue, Saul Lieberman ${ }^{11}$ a établi une comparaison avec les catégoriques hellénistiques de l'ekdosis (version autorisée, publiée) ou du syngramma (le livre au sens propre du terme) et de l'hypomnēma (note destinée à un usage privé). Seule la Bible était un syngramma. Dans l'institut d'enseignement, elle ne devait du reste être lue qu'à partir de pages écrites et ne devait pas être récitée par cœur. À l'inverse, la loi orale - pour autant qu'elle fût fixée par écrit - n'a longtemps existé que sous la forme d' hypomnēmata. Ces derniers ne devaient toutefois pas être utilisés au sein des instituts d'enseignement ou lors de discussions publiques. Toujours est-il que la loi orale a été enseignée et transmise durant toute l'époque des Amoraïm (ca. 200-500 ap. J.-C.) sans support écrit ${ }^{12}$.

6 Les faits mis en avant doivent donc suffire à montrer combien l'analogie « entre le rapport du hadith au Coran et la relation de l'enseignement oral à l'enseignement écrit dans le judaïsme » est discutable.

7 (On notera entre parenthèses que le christianisme primitif a connu une analogie similaire. Dans un premier temps, aucun Évangile ou Nouveau Testament rédigé, ne côtoie encore l'«Écriture (sainte) 》 ou l'Ancien Testament. C'est la parole du "Seigneur » transmise oralement qui possède la plus grande autorité, y compris vis-à-vis de l'«Écriture» ${ }^{13}$. Birger Gerhardsson, dans l'ouvrage cité ${ }^{14}$, a montré qu'il était probable que, pour transmettre la parole du Seigneur, des hypomnēmata aient été utilisés pour soutenir la mémoire.)

Revenons au mode de transmission qu'est l'«enseignement oral» des juifs et des musulmans. La suite de notre propos montrera, par un examen plus approfondi, non seulement que des rapprochements précis peuvent apparaitre sur certains points, mais aussi que nombre des conclusions développées sur le mode de transmission de la Torah orale peuvent devenir fécondes pour explorer certains des aspects correspondants du hadith. (Que l'inverse soit aussi vrai me paraît tout à fait possible: voir notamment infra $\$ 49$ et suiv.). - Il va de soi qu'outre les parallèles, il existe aussi des points de divergence et des évolutions distinctes.

Il convient de montrer tout d'abord que le mode de transmission «oral» - le terme " oral ", comme nous le savons, est à manier cum grano salis - propre au Talmud et au Hadith ont soulevé çà et là des problèmes similaires, suscité des phénomènes similaires et généré des topoi similaires.

De part et d'autre, on débat sur la question de savoir si les aveugles peuvent être considérés comme des transmetteurs fiables; on présuppose ainsi naturellement que le fait que les aveugles ne peuvent vérifier leur savoir au moyen de supports écrits constitue un obstacle à leur reconnaissance comme transmetteurs à part entière ${ }^{15}$.

De part et d'autre, les élèves avaient en effet coutume de prendre des notes en classe. Du côté juif, on utilisait comme matériel d'écriture des tablettes ou des feuillets revêtant la forme de codices (pinaqsiyōth en hébreu, du grec pinakes), autant que des « rouleaux secrets» ( $m^{e}$ gillöth setärìm), c'est-à-dire privés; ils servaient de «livres de 
mémoire" (sifrē zikkārōn $)^{16}$. Du côté musulman, il s'agissait de la même façon de tablettes (alwāhn, sabbūrāt), sur lesquelles les mots écrits pouvaient être facilement effacés ${ }^{17}$, mais aussi de carnets (karārīs, kurrāsa au singulier). Des objections s'élevaient parfois contre l'utilisation de ces derniers, au motif qu'ils ressemblaient à des exemplaires du Coran (mașāhiff) ${ }^{18}$. Aucune trace écrite ne devait donc exister pour l'éternité ${ }^{19}$. Pour cette raison, certains demandaient que les élèves effaçassent ce qui était écrit après l'avoir appris par cœur ${ }^{20}$. De nombreux spécialistes de la tradition ordonnaient dans leur testament que leurs notes fussent détruites après leur mort, brûlées ou enfouies ${ }^{21}$. En revanche, même ceux qui s'opposaient à la mise par écrit n'avaient rien à redire contre ce qu'on appelle les ațāaf (littéralement "pointes / extrémités »). Il s'agit d'écrits dans lesquels seuls le début et la fin des hadiths sont notés ${ }^{22}$. Étant donné que les supports d'écriture étaient rares et n'étaient pas toujours disponibles, les élèves juifs et les élèves musulmans devaient parfois écrire sur les murs $^{23}$. Du côté islamique, nous apprenons en outre que les paumes des mains et les sandales pouvaient être utilisées en guise de support ${ }^{24}$.

Pourtant, de grandes quantités d'hypomnēmata durables durent être produites. De part et d'autre, la masse des notes disponibles pour certains passages ou qui pouvaient être attribuées à certains transmetteurs est exprimée, non sans excès, en charges de chameaux. Comparé aux quatre cents chameaux qui, d'après un certain Mar Zuṭra, étaient chargés de commentaires haggadiques relatifs à un passage $(8,37-9,43) d u$ Premier livre des Chroniques ${ }^{25}$, l'unique charge de chameau contenant des "livres» de 'Abdallāh bin 'Abbās (mort en 687) qui devaient être déposés chez Mūsā ibn 'Uqba (mort en 758) paraît bien modeste ${ }^{26}$.

«Comme ce qui était exposé par les maîtres ne devait pas être mis par écrit pour un usage public, on devait transmettre chaque phrase entendue au nom de celui qui l'avait communiquée [...]. On devait même, si possible, citer des autorités plus anciennes, qui avaient prononcé la phrase en question: si tu peux faire remonter une chaîne de tradition jusqu'à Moïse, fais-le [...] $»^{27}$.

J. Horovitz défendait en son temps le point de vue selon lequel il fallait voir dans cette pratique des écoles juives de l'époque talmudique (des Amoraïm) le modèle de l'isnād (chaîne de transmetteurs qui précède le texte du hadith) ${ }^{28}$. Ce n'est pas exclu. Comme semblent l'établir aujourd'hui les recherches de G. H. A. Juynboll ${ }^{29}$, l'isnād est apparu dans l'Islam durant la deuxième guerre civile (680-692). À cette époque, il dut déjà y avoir suffisamment de convertis issus du judaïsme, qui connaissaient le système d'authentification de la Mishna - définitivement mis par écrit dans l'intervalle - et purent l'introduire dans la tradition islamique. Il est cependant plus probable que nous ayons ici affaire à une évolution parallèle dans les deux cultures. Si les sources écrites font défaut ou ne sont pas reconnues au sein d'une communauté, il n'est pas d'autre possibilité, pour le transmetteur, que d'authentifier, d'« appuyer » (asnada $\rightarrow$ isnād) la phrase prononcée dont il s'agit de prouver la provenance en citant une source orale, autrement dit un garant.

Du côté islamique, comme l'a souligné à juste titre Goldziher ${ }^{30}$, il se forma, à partir de l'opposition à l'écriture des traditions, une querelle entre les adversaires et les partisans de l'écrit, vivace et purement théorique, qui ne parvint pas à interférer avec la pratique, ancrée depuis longtemps, de la mise par écrit. Il n'y a apparemment rien eu de semblable au sein du judaïsme. D'une manière générale, les sentences justifiant la mise par écrit de la loi orale font ici défaut. 
14 Aussi l'interdiction de mettre par écrit la Torah orale n'a-t-elle jamais été formellement levée ${ }^{31}$. Cette situation s'explique à nouveau par le fait que l'époque de rédaction de la Mishna et du Talmud est purement hypothétique et demeure sujette à discussion, tant parmi les savants juifs du Moyen Âge que parmi les érudits juifs ou chrétiens modernes. Pour la Mishna, l'ouvrage fondamental de la loi orale judaïque, la période concernée s'étend entre 200 (au plus tard) et 500 (au plus tôt) ap. J.-C., autrement dit sur trois siècles environ ou plus.

15 La question est alors notamment de savoir si les premières rédactions de la Mishna, celle de Rabbi 'Aqiba (autour de 100 ap. J.-C.) et surtout celle de Rabbi Juda ha-Nasi (mort autour de 200 ap.J.-C.), sont ou non déjà faites par écrit. D’après Saul Lieberman $^{32}$, Rabbi 'Aqiba aurait compilé la nouvelle Mishna en utilisant les hypomnèmata de ses élèves. La "publication » de celle-ci serait passée par une voie purement orale, les transmetteurs (que l'on appelle les tannaïm) récitant les textes appris par cœur dans les instituts d'enseignement. En cas de doute, les tannaïm pouvaient être interrogés sur un texte. La nouvelle Mishna aurait ainsi été publiée en de nombreux " exemplaires », sous la forme de livres vivants. Selon Lieberman, Rabbi Juda a procédé de manière analogue pour sa « nouvelle édition » de la Mishna ${ }^{33}$.

16 Selon une autre conception, que soutient l'auteur de l'article « Mishna » dans la Jewish Encyclopedia $^{34}$, Rabbi Juda aurait, en son temps, lui-même fixé par écrit la Mishna, sans pourtant abolir ainsi complètement l'interdiction de mettre par écrit des halakhōth. La méthode orale d'enseignement se poursuivait en effet, dans la mesure où le maître utilisait la Mishna écrite seulement comme un support de son exposé oral.

Dans le cas des premières compilations de la Mishna, bien qu'elles fussent probablement mises au point à l'aide de notes écrites ${ }^{35}$, il ne s'agit pas encore de « publications » écrites. La publication n'est certainement intervenue que dans le cadre de la rédaction finale du Talmud ${ }^{36}$, peut-être autour de 500 ap. J.-C., ou plus tard - la date précise est là aussi débattue. La matière de l'enseignement s'était en fin de compte tellement développée que sa publication sous la forme d'un "livre " ne pouvait être repoussée plus longtemps ${ }^{37}$.

18 Un problème similaire s'est également présenté dans le développement du Hadith. Sur ce point, la question se pose de savoir si les premiers muṣannaf-s « pré-classiques » (des collections systématiquement organisées par chapitres), dont les plus anciens ont vu le jour un siècle avant les collections canoniques (les Șaḥịh d'al-BuHāàī, mort 870, et de Muslim, mort en 875 ), vers le milieu du VIII ${ }^{\mathrm{e}}$ siècle, existaient déjà sous une forme écrite. Cette question doit être développée plus avant dans la suite de notre propos.

Un des savants qui ont l'honneur de compter parmi les premiers musannifün (compilateurs de muṣannaf) est le transmetteur et théologien bassorien Sa'īd b. Abī 'Arūba (mort en 773) ' $^{38}$ À Bassora (et plus généralement en Irak), on accordait en son temps - ce fut encore le cas ultérieurement - une valeur particulière à la "publication» orale des traditions. Cela signifiait que la plupart des Bassoriens récitaient par cœur les hadiths (et donc ne les lisaient pas). Chacun possédait certes des supports écrits, mais évitait de les utiliser en public. On rapporte au sujet de Sa'īd b. Abī 'Arūba : lam yakun lahū kitāb, innamā kāna yahfaẓu, "il ne possédait (généralement) pas de livres et avait davantage pour habitude de mémoriser ${ }^{39}$. Ce n'est pas un topos, dans la mesure où, s'agissant d'autres savants bassoriens, on précise explicitement le contraire - c'est ainsi le cas de Hammām b. Yahyā (mort en 781), qui était parfois obligé de consulter son livre ${ }^{40}$. Sa'īd conservait-il effectivement l'intégralité de son mușannaf 
exclusivement dans sa mémoire ? C'est a priori peu probable, dans la mesure où les mușannaf-s constituent, à l'instar des spécimens les plus anciens qui nous sont parvenus - les œuvres de 'Abdarrazzāq b. Hammām (mort en 827) et d'lbn Abī Šaiba (mort en 849) -, de très vastes compilations. Et il est avéré que ce ne fut pas le cas: nous apprenons en effet que Sa'î̉ b. Abī 'Arūba avait un scribe, du nom de 'Abdalwahhāb b. 'Ața', qui l'accompagnait et mettait ses livres par écrit ${ }^{41}$.

Il a longtemps été mal perçu, à Bassora, que les savants utilisent leurs hypomnēmata en public et les présentent comme preuves pour authentifier leurs traditions. Le Bassorien Ma'mar b. Rāšìd (mort en 770), qui fut lui aussi l'un des premiers compilateurs de muṣannaf et qui s'était installé à Sanaa, avait pris l'habitude, au Yémen, "de prendre soin de ses livres et de les consulter", puisqu'on n'accordait là-bas aucune valeur à la récitation par cœur. Lors de son séjour dans sa ville natale de Bassora, il se vit cependant contraint de transmettre de mémoire ${ }^{42}$.

De même, le célèbre critique du Hadith bassorien Yahyā b. Sa īid al-Qațțān (mort en 813) aurait encore professé sans lire de notes ${ }^{43}$; pour les hadiths plus longs, il lisait toutefois dans les « livres » de ses élèves ${ }^{44}$.

Dans l'autre centre irakien de Koufa (comme à Médine), on estimait qu'il était souhaitable de transmettre la tradition de mémoire. Le premier auteur d'un mușannaf issu de cette ville, Yahyā b. Zakarīyā' Ibn Abī Zā'ida (mort en 798), transmettait de mémoire ${ }^{45}$. Wakī' b. al-Ğarraḥ (mort en 812), qui prit le mușannaf de Yahyā b. Zakarīyā' Ibn Abī Zā'ida pour modèle de son propre ouvrage, procédait de même ${ }^{46}$.

Ibn Abī Šaiba (mort en 849), un savant originaire de Koufa et l'un des plus anciens mușannifün dont les collections nous soient parvenues, affirme au début de l'un des chapitres de son œuvre monumentale: "Voici ce que je sais par cœur au sujet du Prophète $[. ..] »^{47}$. Cette formulation étonnante montre que certains compilateurs, même à une époque où leurs notes s'étaient développées jusqu'à former des manuscrits composés de plusieurs volumes, étaient encore amenés à présenter ce qui était mis par écrit comme des hypomnēmata.

Comme il a longtemps été proscrit en Irak que les transmetteurs utilisent en public leurs hypomnēmata, il est indiqué dans des traités spéciaux (les awā'il) quels savants avaient, pour la première fois, produit leurs «livres» en public pour authentifier la tradition présentée : ce furent Rauh b. 'Ubāda (mort en 821), de Bassora, et Abū Usāma (Hammād b. Usāma, mort en 817), de Koufa ${ }^{48}$. À l'invitation "Présente tes livres!", Sufyān b. 'Uyaina (mort en 811) aurait au contraire encore répondu : "Je garde (en mémoire) mieux que mes livres ! $»^{49}$.

Lorsque Bagdad, la capitale du califat, prit définitivement le relais des villes de province de Bassora et de Koufa pour devenir le centre des sciences et de l'érudition relative au hadith, on abandonna peu à peu la méthode qui consistait à réciter le Hadith par cœur. Parmi les plus importants transmetteurs bagdadiens de la première moitié du IX siècle, 'Alī b. al-Madīnī (mort en 849), Yahyāa b. Ma'īn (mort en 847) et Aḥmad b. Hanbal (mort en 855), le premier, originaire de Bassora, cultivait encore cette méthode. Aḥmad b. Ḥanbal, à l'inverse, n'en faisait pas grand cas. Il constata à cet égard qu'il préférait le Hadith de 'Abdarrazzāq 'an (d'après) Ma'mar b. Rāšīd, qui avait assidûment utilisé et consulté ses livres, au Hadith de ces Bassoriens - qui, dans la mesure où ils s'en remettaient à leur mémoire, commettaient des erreurs ${ }^{50}$. D'un autre côté, les 
traditions que propagea Ma'mar b. Rāšīd à Bassora auraient contenu des erreurs puisqu'il y professait par cœur ${ }^{51}$.

Ahmad b. Ḥanbal, compilateur d'une collection de hadiths en plusieurs volumes, le Musnad, était tout à fait conscient de l'importance de l'écrit pour son métier. À une remarque de l'un de ses élèves - «Si le Savoir (autrement dit le Hadith, la Tradition) n'était pas noté, il disparaîtrait !»-, il aurait répondu : «Bien sûr. Et sans la mise par écrit de la Tradition, que serions-nous (les transmetteurs) alors ? ${ }^{52}$.

Les biographes de Yahyā b. Ma'in faisaient déjà valoir, non sans éloges, qu'il avait écrit et laissé quantité de «livres » ${ }^{53}$. Il est tout simplement considéré comme le transmetteur qui a mis par écrit, en son temps, plus de hadiths que tout autre ${ }^{54}$.

À Bagdad, comme auparavant dans d'autres centres situés hors d'Irak, on cessa d'exiger que le Hadith fût récité de mémoire. Cette situation résulte d'une évolution naturelle : la matière qu'il s'agissait de maîtriser était devenue si ample qu'il n'était plus possible même en la répartissant sur des heures d'enseignement se succédant à intervalles réguliers - de l'assimiler par cœur, du moins si l'on souhaitait éviter les erreurs.

\section{II.}

Jusqu'à présent, nous avons largement tenu à l'écart la question qui est peut-être la plus intéressante, celle de savoir pour quelles raisons, au sein du judaïsme et de l'Islam, on s'est attaché aussi longtemps - du moins en théorie - à la nécessité de réciter de mémoire la tradition. La réponse nous ramène au point de départ de notre réflexion.

Il est certain qu'au sein du judaïsme, l'idée selon laquelle seule la Bible est destinée à l'« écrit »- et que la Mishna et le Talmud devaient l'accompagner sous la forme d'un enseignement oral - a dominé pendant des siècles. Une conception similaire est attestée dans l'Islam par de nombreux hadiths - des traditions du Prophète, des compagnons ou des successeurs -, dans lesquels le taqyìd al-'ilm, «l'action d'enchaîner le Savoir ", c'est-à-dire la fixation de la tradition au moyen de l'écriture, est prohibé.

31 Voici quelques exemples de ces hadiths. Dans une tradition très connue se rattachant à cet aspect, le Prophète, d'après le témoignage de Abū Sa'î̀ al-Hudrī (un compagnon $d$ Mahomet, mort en 693), aurait prononcé les paroles suivantes: «N'écrivez pas mes paroles, à l'exception du Coran ; mais si quelqu'un a écrit autre chose que le Coran, qu'il l'anéantisse ! $\aleph^{55}$. De même, dans une autre sentence du Prophète, attribuée à Abū Huraira : «Souhaitez-vous un autre livre que le livre de Dieu? Seuls les livres que les peuples qui vous ont précédé (c'est-à dire les juifs et les chrétiens) ont écrits en plus du livre de Dieu les ont induits en erreur $!{ }^{56}$. Dans ce hadith, on peut noter l'allusion à la Mishna des juifs, qui avait été mis par écrit entre-temps.

32 Abū Sa'īì al-Hudrī lui-même aurait répondu, alors qu'on le priait de dicter : « Voulezvous faire de cela des exemplaires du Coran? Votre Prophète avait coutume de nous rapporter (oralement) (kāna yuhaddițunā) ; gardez donc (vous aussi) en mémoire nos propos, comme nous avons gardé en mémoire les propos de votre Prophète ${ }^{57}$.

33 Les successeurs 'Ubaida b. 'Amr as-Salmāni et Ibrāhīm b. Yazīd an-NaHa'î (mort en 715) auraient chacun dit à un élève qui prenait des notes : lā tuHlidanna 'annī kitāban, « Ne consignez pas mes paroles par écrit pour l'éternité ! $»^{58}$. 
34 À ce groupe de traditions s'oppose néanmoins un autre groupe, qui autorise explicitement de prendre des notes. Bien entendu, cette autorisation porte tout d'abord sur les informations destinées à soutenir la mémoire. Elle découle parfois du contenu des hadiths.

Le Prophète - selon le compagnon Abū Huraira (mort 678) -, dans une tradition bien connue se rattachant à cette question, aurait ainsi répondu, à un homme qui se plaignait de la faiblesse de sa mémoire : "Soutiens ta mémoire au moyen de ta main droite ! ${ }^{59}$. Le petit-fils du Prophète, al- Hasan b. 'Alī (mort environ en 670), aurait également conseillé à ses fils et à ses neveux : "Apprenez le Savoir (c'est-à-dire la Tradition). Que celui d'entre vous qui n'est pas capable de le transmettre (de mémoire) le mette cependant par écrit et le dépose chez lui $»^{60}$.

Toutefois, les hadiths de ce dernier groupe ne sauraient occulter le fait que le rejet de l'écriture, dans l'autre groupe, renvoie aussi explicitement aux hypomnēmata: ceux-ci devaient en effet, si d'aventure l'on en avait produit, être effacés ou détruits.

Pour quelles raisons, dans cette conception, seul le Coran devait-il être écrit, la Tradition devant au contraire être conservée et transmise de mémoire? Pourquoi ne devait-il pas y avoir, parallèlement au Coran, un autre enseignement écrit?

Les tentatives d'explication formulées jusqu'à présent s'en tiennent étroitement, dans leur majorité, au texte des traditions: elles procèdent de l'interprétation de leur contenu. Il en alla de même, de manière compréhensible, des explications produites par les anciens savants musulmans. Les raisons avancées par eux pour justifier cette aversion à l'égard de la mise par écrit sont généralement les suivantes :

39 1) la crainte que se forme un second livre, similaire au Coran, ou bien que les hadiths écrits se mélangent au texte du Coran (en particulier alors que la révélation était encore en cours) ${ }^{61}$. La tradition décrit ainsi trois de cinq rédacteurs du texte coranique, Zaid b. Tābit (mort en 666, Médine), 'Abdallāh b. Mas'ūd (mort en 653, Koufa) et Abū Mūsā al-Aš arī (mort vers 662, Bassora) comme de farouches adversaires de la mise par écrit de leurs traditions et de leurs paroles ${ }^{62}$.

40 2) la crainte que les fidèles se laissent détourner du Coran par le Hadith écrit. Les juifs et les chrétiens se sont lourdement rendus coupables en suivant d'autres livres que la seule révélation, et il fallait dès lors éviter les mêmes funestes erreurs ${ }^{63}$.

41 3) la crainte que les fidèles se fient trop à l'écrit, qui est en effet éphémère, et qu'ils ne mémorisent pas suffisamment les paroles qu'il convient de retenir ${ }^{64}$.

4) la crainte que les traditions puissent parvenir à ceux qui ne sont pas autorisés à y accéder, qu'elles puissent tomber entre de mauvaises mains ${ }^{65}$. Cette crainte fut sûrement aussi la raison pour laquelle certains transmetteurs demandaient dans leur testament que leurs notes fussent détruites après leur mort ${ }^{66}$.

Les critiques du Hadith ultérieurs (Ibn Qutaiba, al-Hațīb al-Bag̉dādī, Ibn 'Abdalbarr, Ibn Hağar), pour qui la fixation et la rédaction de la Tradition étaient un fait accompli, ont tenté de concilier les hadiths hostiles à la mise par écrit et ceux qui étaient favorables à l'écriture. On suggérait par exemple que le second groupe de hadiths s'était formé, à la différence du premier groupe, à une autre période que celle durant laquelle la révélation était en cours, ou bien à époque ultérieure. En admettant que les hadiths favorables à l'écriture se soient formés à une époque ultérieure, on peut alors résoudre cette contradiction en invoquant le fait qu'une sunna (pratique du Prophète) en abroge une autre ${ }^{67}$. Ou bien alors on explique que Mahomet avait accordé à certaines 
personnes habiles dans l'art de l'écriture, à l'instar de 'Abdallāh b. 'Amr b. al-'Āṣ (m. en 684), la permission d'écrire, et non à d'autres, moins compétents en la matière ${ }^{68}$. Une autre possibilité de conciliation consiste à affirmer que l'interdiction ne valait que pour les personnes dont on pouvait redouter qu'elles s'en remettent trop à ce qui est écrit, tandis que la permission d'écrire concernait au contraire celles dont on était sûr qu'elles pouvaient se prémunir de ce travers ${ }^{69}$. On peut enfin rencontrer l'argument selon lequel les premiers transmetteurs (Ibn 'Abbās, aš-Ša'bī, az-Zuhrī, Qatāda, etc.) auraient été de purs Arabes et, en tant que tels, dotés d'une excellente mémoire. Tout cela aurait changé à une époque ultérieure, et la mise par écrit serait tout simplement devenue, pour cette raison et du fait de l'ampleur de la matière, une nécessité : sans l'écriture, une large part de la tradition se serait perdue ${ }^{70}$.

Revenons aux raisons invoquées pour justifier les réticences vis-à-vis de la mise par écrit de hadiths. Quant aux explications apportées par divers savants égyptiens modernes, qui ne vont guère plus loin que leurs prédécesseurs médiévaux, on peut ici renvoyer à un chapitre particulier de l'ouvrage de G. H. A. Juynboll, The Authenticity of the Tradition Literature ${ }^{71}$.

Les essais d'explication de Nabia Abbott et de Fuat Sezgins s'inscrivent également dans cette perspective ${ }^{72}$.

Ignaz Goldziher a développé plusieurs pistes pour comprendre le phénomène. Il se tient plus près des sources dans l'un de ses (derniers) travaux, intitulé «Kämpfe um die Stellung des Hadīt im Islam» («Disputes sur la position du Hadith en Islam ») ${ }^{73}$. Parmi l'un des motifs de l'aversion contre l'écrit, il évoque dans cet article le souci des personnes pieuses de ne pas altérer, de manière involontaire, mais pourtant coupable, le texte original $\mathrm{du}$ hadith $^{74}$. Il voit également une autre raison dans l'aversion largement répandue à l'égard de tels hadiths qui se réclament de l'autorité du Coran ${ }^{75}$. Il attire enfin l'attention, comme troisième motif ${ }^{76}$, sur "l'aspect de tendance " (répression de traditions gênantes). Tous ces arguments se rattachent certes, comme le sait très bien Goldziher ${ }^{77}$, également à la diffusion orale des hadiths correspondants. Selon lui, pourtant, ils s'appliquent d'autant plus à leur consignation par écrit.

Dans l'essai d'explication proposé dans son livre Muhammedanische Studien ${ }^{78}$, Goldziher se tient plus éloigné des sources. Il y évoque les ambitions des anciennes écoles du ra' $y^{79}$ « d'être aussi peu entravées que possible, dans la libre élaboration de la loi, par des leges scriptae ». Parmi les premiers adversaires de la mise par écrit des traditions (et du ra'y) fuqaha' (docteurs de la loi ; juristes) et qadis (juges) se distinguent effectivement. Pour cette raison, l'analyse de Goldziher, pour autant qu'on ne la généralise à l'excès, ne semble aucunement infondée. Néanmoins, on peut aussi trouver parmi les ahl ar-ra'y (adeptes du ra'y) - notamment à partir du milieu du VIII ${ }^{\mathrm{e}}$ siècle -, outre des adversaires, des partisans de la diffusion par écrit de la tradition ${ }^{80}$. À une époque ultérieure, il est en effet de plus en plus fréquent que les savants transmettent des hadiths non plus seulement pour appuyer leur propre opinion, mais bien plutôt dans le simple empressement mis à les collecter, qui les conduit même à propager des traditions allant à rebours de leur propre conviction et se contredisant l'une l'autre.

Dans la suite de notre propos, cette question sera à nouveau analysée. L'essai de réponse que nous formulerons vise non à remplacer, mais à compléter les propositions antérieures. L'argument central que nous développerons a été inspiré, d'une part, par la remarque de Goldziher sur «l'aspect de la tendance », que l'on peut parfois percevoir 
dans les réticences à l'égard de l'écrit, ainsi que, d'autre part, par la réponse que les spécialistes du judaïsme ont formulée sur cette question dans leur propre domaine.

D'une manière générale, on rencontre cinq propositions d'explication dans la littérature spécialisée sur le judaïsme. (Elles ont été rassemblées par Julius Kaplan ${ }^{81}$ ). Sur cette question, il semble que nous ayons affaire, dans la plupart des cas, à de pures conjectures. On n'a guère pu s'appuyer, à l'évidence, sur des témoignages directs, textuels ou d'une autre nature (selon Kaplan, ibid.).

50 Les théories moins fréquemment soutenues affirment que :

1) L'interdiction de l'écrit «permettait certainement de réserver l'étude de la loi aux cercles étroits des savants reconnus et compétents».

2) L'interdiction de l'écrit «s'appuyait sur un fondement mystique, lié au sentiment qu'il ne devait y avoir qu'une seule Torah ».

3) «Elle constituait une mesure de précaution contre les interpolations hérétiques ou l'introduction en contrebande, dans les académies, d'œuvres tout entières, présentant elles aussi un caractère douteux. "

4) L'interdiction de l'écrit est motivée par «le manque de fiabilité du mot écrit, perçu comme un outil traître et malhonnête $»^{82}$.

51 S'agissant des deux premiers points, on rencontre expressis verbis, parmi les savants musulmans, les mêmes arguments ou des arguments similaires pour justifier l'interdiction de l'écrit ${ }^{83}$. Le point 4 constitue l'argument principal des savants musulmans pour justifier la nécessité de la «tradition par audition» (ar-riwāya al$m a s m \bar{u}^{\prime} a$ ), ou plutôt le rejet d'une "tradition purement recopiée» (appelée simplement, la plupart du temps, kitāb[a]) (voir infra $\$ 87)^{84}$. Pour le point 3 , on ne trouve pas de parallèle, semble-t-il.

52 Cependant, la théorie qui est de loin la plus fréquemment soutenue par les spécialistes du judaïsme affirme que :

5) Selon la volonté originale des docteurs de la loi, l'enseignement oral ne devait pas être un enseignement unitaire, achevé, définitif. L'interdiction d'en fixer le contenu par écrit aurait permis de conserver une certaine souplesse : la possibilité de modifier les lois, de les adapter, au besoin de les réviser, et même d'abroger certaines prescriptions ${ }^{85}$.

53 Il ne fait aucun doute qu'au sein de l'Islam, il y a eu très souvent, derrière l'aversion pour l'écrit, une attitude similaire, même si cette lecture ne fut que rarement exprimée ouvertement, comme on peut s'y attendre. Il existe néanmoins certains témoignages qui vont très clairement dans ce sens.

54 1) Le calife 'Umar (règne : 634-644), d'après le récit d'Ibn Šihāb az-Zuhrī (mort en 742) aurait à un moment envisagé de faire mettre par écrit les sunan (c'est-à-dire les pratiques [exemplaires] du Prophète) ; après un temps de réflexion, il aurait cependant rejeté ce projet ${ }^{86}$. Par la suite, 'Umar se présente à nous comme un farouche adversaire de la diffusion, non seulement écrite, mais aussi orale des hadiths. De même, il aurait interdit de rendre publique (zähiran) une sentence de Mahomet, dont plusieurs des compagnons du Prophète lui avaient confirmé l'authenticité, au motif que le contenu de celle-ci aurait restreint le calife dans sa liberté d'action dans l'une de ses entreprises $^{87}$. La position extrême de 'Umar, hostile à la conservation et à la transmission écrites et orales de la tradition n'a pu obtenir la reconnaissance de plus larges cercles. Le «scripturalisme » (Michael Cook) est encore incarné, à une époque 
ultérieure, par quelques extrémistes (quelques mu'tazilites, les Hुāriğites) ${ }^{88}$; d'une manière générale, cependant, un point de vue médian entre les extrêmes a très vite prévalu parmi les savants, pour une longue période, selon lequel le hadith, en tant qu'« enseignement oral », devait côtoyer l'« enseignement écrit » qu'est le Coran.

2) Un jour, le fils de 'Abdallāh b. Mas' ūd (mort 653), lequel est aussi souvent mentionné parmi les adversaires de la mise par écrit des traditions, aurait attiré son attention sur le fait qu'il avait, dans une précédente occasion, récité différemment un hadith. À la question de savoir comment il en était venu à soutenir pareille affirmation, le fils aurait répondu: "Je l'avais (alors) noté. » Sur ce, Ibn Mas'ūd lui aurait ordonné d'apporter son cahier, pour qu'il fût effacé sur le champ ${ }^{89}$.

3) Le juriste mecquois 'Amr b. Dīnār (mort en 743) ne tolérait pas que ses élèves transcrivissent des traditions ou bien ses propres opinions juridiques $\left(r a^{\prime} y\right)$ : « Demain, peut-être, je me serai déjà détourné de lui [mon $\left.r a^{\prime} y\right] »^{90}$. (Que l'on se rappelle ici l'idée, développée par Goldziher, d'un intérêt des ahl ar-ra'y dans l'interdiction de l'écrit.)

4) À cette question se rattache également le mot attribué à al-Auzā'i (mort en 774), fondateur d'un madhab (école juridique). Il aurait déclaré un jour: "Cette science (c'est-à-dire le Hadith) était (autrefois) une noble affaire, puisqu'on la recevait et on la mémorisait ensemble à l'école. Toutefois, lorsqu'elle passa dans les livres, elle perdit de son lustre et elle parvint à des mauvaises personnes (ilä gair ahlihī) »"1. La métaphore du "lustre ", censée illustrer la singularité du Hadith non codifié, n'évoque certes non seulement son caractère malléable, changeant, mais renvoie aussi à une dimension similaire, à ce que l'enseignement de personne à personne, avant que ne s'impose l'apprentissage par les livres, comporte de direct, de vivant, de spontané, et dont on déplore ici la perte définitive, perçue comme un fait désormais irrévocable. (Il me semble que ce dernier aspect - outre la souplesse - a occupé une place de tout premier plan dans la transmission orale de la parole du Seigneur au sein du christianisme primitif, voir supra § 7.) Le second argument d'al-Auzā'î̀ (« elle parvint à des mauvaises personnes ») évoque cette autre réponse que les spécialistes du judaïsme, dans leur propre domaine, ont parfois apportée à la question ici concernée : « Elle (l'interdiction de l'écrit) permettait certainement de réserver l'étude de la loi aux cercles étroits des savants reconnus et compétents $»^{92}$.

III.

D'après la Tradition, le calife omeyyade 'Umar II (règne : 717-720) aurait ordonné la première collection officielle du hadith (tadwin), "par crainte de voir la tradition disparaître et ceux qui la portent s'éteindre $»^{93}$, après que certains des Omeyyades qui l'ont précédé auraient parfois déjà fait mettre par écrit ou collecter des traditions (à l'instar de Marwan I [règne: 684-685] ${ }^{94}$ et surtout du père de 'Umar II, 'Abdal'aziz b. Marwān [mort en 704] ${ }^{95}$ ).

La situation avait profondément évolué depuis la mort de 'Umar I. Il ne restait plus, ou presque plus de compagnons du Prophète qui auraient pu divulguer des hadiths gênants pour les Omeyyades. En revanche, une entreprise de rédaction sous l'égide des Omeyyades ne pouvait apporter aux souverains que des avantages. Pourtant, des motifs purement religieux peuvent, comme le veut la Tradition, avoir constitué la préoccupation première de 'Umar II. 
Si l'on en croit la Tradition, 'Umar II aurait joué pour le Hadith un rôle similaire à celui de 'Uțmān (règne : 644-656) pour le Coran.

Le premier savant auquel 'Umar II aurait confié cette mission aurait été Abū Bakr b. 'Umar b. Hazm (mort en 737) ${ }^{96}$. Cependant, le premier à avoir mis à exécution et mené à bien le projet aurait été le Médinois Ibn Šihāb az-Zuhrī (mort en 742). «Le premier à avoir collecté (à grande échelle) et écrit le Savoir (c'est-à-dire la Tradition) est Ibn Šihāb (awwal man dawwana al-'ilm wa-katabahū Ibn Šihāb) ${ }^{97}$. Cet homme, qui a par ailleurs joué un rôle déterminant dans la diffusion du Hadith, semble pour cette raison avoir eu des scrupules toute sa vie. C'est du moins ce que font apparaître un certain nombre de paroles qu'il a transmises ou qui ont été rapportées à son sujet. La sentence d'az-Zuhrī la plus fréquemment citée et la plus importante sur ce point est la suivante :

« Nous refusions de consigner le Savoir (c'est-à-dire la Tradition) par écrit, jusqu'à que ces souverains nous aient obligés à le faire. Mais, à présent, nous sommes d'avis que nous ne devrions plus l'interdire (c'est-à-dire la mise par écrit de la tradition) à aucun musulman. » (kunnā nakrahū kitāb al-'ilm hattā akrahanā 'alaihi hä'ulā' i lumară $\bar{a}^{\prime}$ fa-ra'ainā allā namna' ahū ahadan min al-muslimin) ${ }^{98}$.

\section{Premier excursus : kariha al-kitāb(a), « il éprouvait de l'aversion envers l'écrit »}

Il est absolument certain que la traduction utilisée plus haut est correcte, à la différence de celle qui est proposée dans GAS, vol. 1, p. 281 : «Nous étions réticents à l'idée de transmettre les hadiths sous la forme de la méthode de kitāb (autrement dit de simplement recopier des textes [...], sans les lire devant le maître ou sans les avoir entendus de sa bouche) ». Le mot kitāb(a) peut certes désigner, dans un autre contexte, la transmission non autorisée par le biais du seul recopiage, comme dans la formule id $\underline{d} \bar{a}$ haddața ('Amr b. Šu'aib) 'an abīhi 'an ğaddihī fa-huwa kitāb, wa-min hunā ğă'a da'fuhū , "Quand ('Amr b. Šu'aib) transmet de son père et de son grand-père, c'est "livre" (c'està-dire de la transmission écrite), et c'est de là que provient sa faiblesse $»^{99}$; ce n'est toutefois pas le sens qu'elle revêt dans l'expression kariha al-kitāb. Ce constat est valable d'une manière générale. Quatre exemples l'attestent : « Ismā̄īl (Ibn 'Ulaiya) a dit : "On (c'est-à-dire nos honnêtes prédécesseurs) éprouvait de l'aversion envers la mise par écrit (karihū al-kitāb), car ceux qui vivaient avant eux (c'est-à-dire les juifs et les chrétiens) avaient respecté et admiré les livres. Et l'on refusait que l'on se laissât détourner par eux (par les livres) du Coran". »100. «A A hmad b. Ḥanbal a dit : “Je refuse de consigner par écrit les paroles de celui qui a fait preuve de complaisance durant la Mihnna ${ }^{101}$ (akrahu al-kitāba 'amman ağāba fi l- mihnna)". »102. " ('Alqama b. Waqqās) dit : "Ne sais-tu pas que l'écrit (al-kitāb) est méprisé ?" Il (Masrūq) répondit: "Si. Je ne voudrais apprendre (les traditions) que par cœur et je les brûlerai ensuite". »" ${ }^{103}$. «Ibrāhīm (anNaHa $\left.{ }^{\prime} \bar{i}\right)$ refusait d'écrire les hadiths sur des carnets (kāna yakrahu an yaktuba al-hadīt fi lkarārīs). $»^{104}$. Dans les quatre cas mentionnés, il serait absurde de traduire kitāb(a) par «mode de transmission fondé sur le seul recopiage ». En fin de compte, le constat est également valable pour des titres de chapitres comme Bāb dikr karāhiyat kitāb(at) al-'ilm

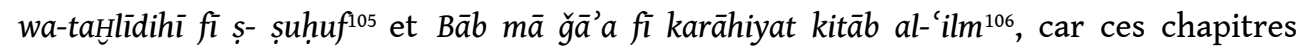
rassemblent des hadiths où l'on prend position contre l'écrit, et non contre le mode de transmission que constitue les kitāba. 


\section{Deuxième excursus : Y a-t-il eu une collection de hadiths initiée par az-Zuhrī pour le compte des Omeyyades ?} évoquant les efforts de 'Umar II pour faire codifier le hadith. "La postérité, dans son admiration ", aurait cherché "à associer étroitement les pieux califes [Omeyyades] à la littérature de la tradition de l'Islam $»^{107}$. À cette vision s'oppose toutefois le fait que la tradition mentionnée plus haut («Nous refusions de consigner le Savoir par écrit, jusqu'à que ces souverains nous aient obligés à le faire ») possède probablement un noyau d'authenticité et est en tout état de cause ancienne. Elle est déjà citée à l'identique par le disciple d'az-Zuhrī, Ma'mar b. Rāšīd (mort en 770), dans son recueil de traditions $K$. al-Ğām $\imath^{-{ }^{\prime} 108}$. Il est totalement improbable que Ma'mar l'ait inventée - par exemple pour apporter du crédit à son activité en tant que mușannif (compilateur d'un mușannaf) -, étant donné qu'il invoque également dans son Bāb kitāb al-'ilm (Chapître sur la mise par écrit du hadith) de son recueil, comme le font aussi des compilateurs ultérieurs, non seulement des hadiths favorables à l'écrit (au nombre de trois), mais aussi des hadiths qui lui sont hostiles (quatre!) ${ }^{109}$. Toutefois, on ne saurait exclure que la pique adressée aux Omeyyades dans la parole rapportée (" ces souverains nous ont obligés ») repose sur une déformation tendancieuse de Ma'mar), ou bien d'az-Zuhrī luimême. Cela ne change rien au fait dont il est question, à savoir qu'az-Zuhrī a été le premier à mettre la tradition par écrit dans une vaste collection (tadwin) pour le compte des Omeyyades. Dans la parole rapportée, ce fait est manifestement présenté comme connu de tous et par conséquent comme historique et, pour cette raison, n'est pas douteux.

$\star \star \star$

az-Zuhrī avait coutume de noter sans réserve un grand nombre de hadiths ${ }^{110}$, la réalisation de la mission confiée par le calife dut revenir pour lui à briser un tabou, eu égard au consensus en vigueur depuis des décennies, selon lequel seul le «Livre", le Coran, devait faire l'objet d'une recension officielle, à l'inverse de l'« enseignement oral », le Hadith. Peut-être a-t-il mis en circulation la tradition mentionnée plus haut d'après laquelle 'Umar I abandonna finalement son projet initial consistant à faire rédiger le Hadith - dans l'espoir d'en dissuader son commanditaire?

Une fois que la collection fut finalisée, 'Umar II en aurait fait fabriquer des copies sur des feuillets, une tâche une nouvelle fois confiée à az-Zuhrī. Sur ce, continue le récit, il en aurait fait envoyer un exemplaire dans chaque province des territoires sur lesquels s'étendait son autorité - on peut à bon droit douter de l'historicité de cette information, puisqu'elle semble complètement modelée d'après le récit des dispositions prises par 'Uțmān une fois la recension du Coran achevée. Du reste, il est plus probable que la collection d'az-Zuhrī fut réalisée ou du moins achevée seulement après la mort de 'Umar II.

Toutefois, az-Zuhrī a lui-même "publié » les matériaux qu'il avait réunis, alors qu'i travaillait comme précepteur des princes sous Hišām (724-743). Cela aussi semble lui avoir posé des problèmes, car il aurait dit :

«Les souverains m'ont fait mettre par écrit (istaktabanī) [la Tradition]. Par la suite,

c'est moi qui les (c'est-à-dire les souverains, en tant que princes) ai fait recopier ( $f a$ -

Trivium, 29 | 2019 
aktabtuhum). À présent, maintenant que les souverains ont écrit (la Tradition), j'ai

honte devant Dieu de ne pas l'écrire pour d'autres qu'eux. $»^{111}$. généralement en Syrie -, la mise par écrit de hadiths, même en vue d'un usage public, ne pouvait plus être considérée comme proscrite. Un élève rapporte: "Nous ne cherchions pas à écrire auprès d'az-Zuhrī, jusqu'à ce que Hišām l'y obligea. C'est alors qu'il écrivit pour les fils de celui-ci. Et désormais, les gens écrivent le Hadith. ${ }^{112}$. La contrainte exercée sur lui par les souverains ne fut pourtant pas l'unique argument au moyen duquel az-Zuhrī chercha à justifier ce qui lui avait lui aussi longtemps paru scandaleux, à savoir la rédaction et la diffusion officielles du Hadith. Il a également invoqué d'autres raisons : «N'étaient les hadiths qui nous viennent de l'Est, que nous rejetons et ne connaissons pas, je n'aurais pas mis par écrit le Hadith et n'aurais pas permis qu'on le mette par écrit. $»^{113}$. Ici se manifeste l'opposition entre l'Est et l'Ouest, c'est-à-dire entre l'Irak et la Syrie, qui nous occupera dans la prochaine partie de notre propos.

\section{IV.}

Si même az-Zuhrī, un partisan et ami des Omeyyades, éprouve initialement des réticences quant au projet de rédiger officiellement la Tradition, il faut s'attendre à ce que cette entreprise suscite une opposition en dehors de la sphère du pouvoir des Omeyyades, et notamment dans l'Irak hostile à cette dynastie. Pourtant, on ne rencontre pas d'attaques directes, formulées explicitement, contre ce projet. L'opposition semble toutefois s'être manifestée davantage de manière indirecte, sous une double forme. D'une part, des hadiths plus fortement dirigés contre la conservation par écrit de la tradition sont mis en circulation à cette époque. Il se peut parfaitement qu'une discussion de moindre ampleur sur ce thème soit déjà intervenue au $\mathrm{I}^{\mathrm{er}}$ siècle de l'Hégire (VII siècle de notre ère). L'analyse des isnād-s des hadiths dont il est ici question, selon la méthode de Schacht/Juynboll, qui vise à déterminer le plus récent transmetteur commun (common link; CL) ayant diffusé le hadith concerné, montre toutefois sans équivoque que ce n'est qu'au tournant du II siècle de l'Hégire (donc vers 720 , à la mort de 'Umar II) que la discussion prit toute son ampleur et se prolongea ensuite durant quelques décennies. Elle révèle aussi que les plus récents transmetteurs communs (common links), parmi ceux qui prirent position contre la mise par écrit, étaient majoritairement - mais non exclusivement - de Bassora, de Koufa ou de Médine. Il est important que les hadiths des compagnons (et probablement également les traditions des successeurs) sont plus anciens que les hadiths du Prophète. Il suffit ici d'évoquer, pour les premiers, le bassorien Abū Naḍra (al-Mundir b. Mālik, mort en $\left.727^{114}\right)$, qui mit en circulation le hadith attribué à Abū Sa īd al-Hudrī, son garant direct («Voulez-vous faire de cela des exemplaires du Coran? [...]»: voir diagramme II 1), ainsi que le cadi de Koufa Abū Burda (mort en 722 $2^{115}$ ), qui transmit le hadith attribué à Abū Abū Mūsā al-Aš arī ( "J'ai écrit d'après mon père de nombreux "livres”, mais il les a détruits [...] $\left.\aleph^{116}\right)$. Les hadiths du Prophète contre la mise par écrit des traditions - au nombre de quatre, à première vue - semblent être associés aux plus récents transmetteurs communs suivants :

(I 1) le Bassorien Hammām b. Yaḥyā (mort en 781 ; Tahdīib, vol., 11/60 et suiv.) (Taqyìd, p. 29-32 ; cf. supra $\$ 29$ et suiv. ; diagramme I 1), 
(I 2) Sufyān b. 'Uyaina (mort en 811), originaire de Koufa, mais installé à La Mecque (Taqyid, p. 32-33; diagramme I 2),

(I 3) le Médinois 'Abdarrahmān b. Zaid b. Aslam (mort en 798; GAS 1/38) (Taqyĩd, p. 33-35; cf. supra $\$ 31$; diagramme I 3) et

(I 4) le Médinois Katiir b. Zaid al-Aslamī (mort en 774 ; Tahdïib, vol., 8/370 et suiv.) (Taqyīd , p. 35 ; diagramme I 4).

Il est certain qu'il s'agit à l'origine, pour les cas (1) à (3), du même hadith, qui fut seulement transmis dans une formulation différente par chacun des transmetteurs désignés. L'isnād commence à chaque fois ainsi : le Prophète - Abū Sa 'î̀ al-Hुudrī - 'Ațā' b. Yasār - Zaid b. Aslam (I 1 - I 2), ou bien : le Prophète - Abū Huraira - 'Ațā' b. Yasār Zaid b. Aslam (I 3). Les plus récents transmetteurs communs mentionnés plus haut deviennent ainsi les plus récents transmetteurs de second degré (partial common links, dans la terminologie de Juynboll), et le faqih (juriste) médinois Zaid b. Aslam se relève être en fait le plus récent transmetteur commun (mort en $753^{117}$ ). Il est connu - et contesté - pour avoir eu l'habitude d'exprimer son ra'y (sa propre opinion juridique) dans son exégèse du Coran ${ }^{118}$. Les deux hadiths du Prophète qu'il nous reste à présent à examiner - c'est-à-dire I 1-3 et I 4 - ont donc été mis en circulation à Médine vers le milieu du VIII siècle. Le premier - indépendamment du fait qu'il fut «diffusé » dans cette ville de nouveau une génération plus tard - fut « exporté » et repris à Bassora et à La Mecque dans des versions quelque peu différentes.

69 (Que le propagateur de l'un des premiers hadiths des compagnons défavorables à la mise par écrit des traditions, Abū Burda, était cadi, et que le propagateur du plus célèbre hadith du Prophète ici concerné, Zaid $b$. Aslam, fut au demeurant un partisan particulièrement éminent de l'ahl ar-ra'y (partisans de la propre opinion juridique) plaide une nouvelle fois en faveur de l'idée, développée par Goldziher, d'un intérêt de l' ahl ar-ra'y dans un mode de reproduction purement oral du hadith.)

70 Pour de plus amples détails au sujet de ces hadiths, voir les commentaires sur les diagrammes.

71 L'autre forme d'opposition à la rédaction du hadith ordonnée par les Omeyyades consista en ceci que l'on manifesta ostensiblement - notamment dans les centres irakiens - son attachement à l'apprentissage par cœur des traditions. Des exemples de spécialistes bassoriens de la Tradition qui incarnèrent ce point de vue, ou de mușannifün (compilateurs d'un mușannaf, c'est-à-dire une collection divisée en chapitres systématiques) de Bassora ou de Koufa qui récitaient leurs œuvres sans s'appuyer sur un « livre » ont été apportés plus haut ( $\$ 19$ et suiv.). D’autres preuves peuvent ici être avancées. Elles sont notamment destinées à montrer que les anciens savants musulmans eux-mêmes associaient la mémorisation du hadith aux spécialistes de la tradition des villes irakiennes.

72 Aḥmad b. Ḥanbal désigne le mode de conservation de la tradition fondé sur le souvenir comme le madhab (la méthode) des Bassoriens ${ }^{119}$. Il rapporte comment un spécialiste de la Tradition et théologien bassorien, Ibn 'Ulaiya (mort en $808^{120}$ ), s'est ému d'un hadith du Prophète favorable à la mise par écrit (un hadith de La Mecque, mis en circulation par 'Amr b. Šu'aib'121). Ahmad b. Ḥanbal décrit Qatāda b. Di'āma (mort en 736 ${ }^{122}$ ), luimême bassorien et aveugle, comme étant un meilleur "gardien de la Tradition » que les gens de Bassora (ahfaz min ahl al-Bașra) ${ }^{123}$. C'est aussi Ahmad b. Ḥanbal qui affirmait préférer les hadiths de 'Abdarrazzāq d'après Ma'mar à celui des Bassoriens (qui, parce qu'ils s'appuyaient sur leur mémoire, commettaient des erreurs). 
73 Mais les «gardiens du Hadith» de Koufa (huffāz al-Kūfìyin lil-hadīt) sont également réputés ${ }^{124}$. On louait le Koufien al-A'maš (mort en 765 ) d'avoir été, en son temps, le gardien des traditions des gens de cette ville - il n'avait bien sûr « aucun livre » (kāna muhaddit ahl al-Kūfa fi zamānihì wa-lam yakun lahū kitāb). Il aurait été, parmi ses compagnons, "le plus éminent lecteur du Coran et le meilleur "gardien" du hadith" (kāna aqra' ahum lil-Qur'ān wa-ahfa-zahum lil- hadīt $)^{125}$.

74 Le rejet de la mise par écrit des traditions, exprimé de manière particulièrement agressive en Irak, peut s'expliquer ainsi par l'opposition entre les villes anti-omeyyades de Bassora, Koufa et Médine, et la ville pro-omeyyade de Damas. Hors de Syrie, on n'était pas partout enclin à accepter des hadiths qui avaient été codifiés et propagés sous l'égide de la puissance omeyyade - nous avons observé (\$ 61,67) que l'on racontait à propos d'az-Zuhrī qu'il s'était parfois vu confronté à la pression des souverains de reconnaître des hadiths de leur convenance ${ }^{126}$.

Peut-être redoutait-on, à une époque où la communauté musulmane était sur le point de se déliter en une pluralité de sectes et d'orientations théologiques, d'hypothéquer définitivement l'unité dans l'Islam, si chaque groupe religieux et politique et même chaque savant suivait l'exemple omeyyade et diffusait publiquement, sous une forme écrite, sa propre collection de hadiths. Le danger que cette tendance ne se cristallisât en des schismes était de toute façon moindre dans la cadre d'un " enseignement oral " plus souple. Tant que celui-ci n'est pas «fixé " par écrit, on pouvait s'abandonner à l'illusion que la tradition, tout autant que le Coran (l'« enseignement écrit»), était malgré tout « une ».

Toutefois, un autre élément aurait pu contribuer au rejet de la mise par écrit. Les spécialistes bassoriens de la tradition, qui étaient aussi, très souvent, des théologiens et pour la plupart des qadarites ${ }^{127}$ (par exemple Ibn 'Ulaiya et de Sa'īd b. Abī 'Arūba), avaient pour habitude et appréciaient de manier dans leurs discussions un « enseignement oral » souple. Il en va de même pour les savants des villes de Koufa et Médine, fortement marquées par le chiisme. Un enseignement oral offrait, vis-à-vis d'un (second) enseignement écrit, maints avantages lorsqu'il s'agissait de défendre ses propres positions et de réfuter les points de vue adverses. Pour un «enseignement écrit ", le Coran suffisait: le texte de celui-ci était fixe et définitif, et un corps de savants, les qurrā' (lecteurs du Coran), veillait jalousement sur la conservation fidèle et la transmission scrupuleuse du texte. À l'inverse, on pouvait aisément adapter des préceptes transmis uniquement de manière orale, par le biais d'ajouts, d'omissions, de remaniements et d'altérations tendancieux, mais aussi, parfois, en falsifiant certains hadiths. Les recherches de Josef van Ess et de Michael Cook $^{128}$ montrent que ces phénomènes se sont effectivement produits, mais aussi selon quelles modalités ils se produisirent. La volonté de conserver une certaine souplesse, de ne pas trancher, a assurément joué un rôle dans l'effort pour maintenir le Hadith sous la forme d'un enseignement oral. Dans la phase finale de cette évolution, la transmission par cœur des hadiths, notamment à Bassora, semble n'avoir plus été pratiquée que comme une activité sportive.

77 Où en étaient cependant les partisans de la mise par écrit des traditions? L'analyse des isnād-s des hadiths concernés montre que des thèses favorables à une version écrite étaient déjà répandues au $\mathrm{I}^{\mathrm{er}}$ siècle de l'Hégire ( $\mathrm{VII}^{\mathrm{e}}$ siècle de notre ère). Le nom de 'Abdallāh b. 'Amr b. al-'Āṣ (mort en 684'129), compagnon du Prophète mecquois, se distingue ici à maints égards, qu'il soit cité comme transmetteur originel ${ }^{130}$, ou bien que 
sa personne et son goût de l'écriture soient l'objet de la sentence ${ }^{131}$. Dans un cas, il est peut-être aussi le premier et le plus récent transmetteur commun ${ }^{132}$. 'Abdallāh b. 'Amr possédait une șahîfa, c'est-à-dire un feuillet sur lequel il avait noté des traditions relatives au Prophète et aux compagnons. Il ne conservait toutefois pas cette șahîfa - la plus célèbre du genre - en secret, ainsi que les autres avaient coutume de conserver leurs notes, mais il se vantait d'elle en public. Il lui donna même un nom, aṣ-șādiqa, « la véridique ", et elle fait l'objet d'une tradition particulière souvent citée, attribuée à 'Abdallāh comme premier transmetteur ${ }^{133}$. Cette șahîifa fut ensuite léguée de père en fils au sein de la famille de 'Abdallāh b. 'Amr - nous allons entendre à nouveau parler d'elle.

Cependant, la diffusion des hadiths favorables à la conservation de la Tradition au moyen de l'écrit s'est produite au cours du siècle suivant, soit le II ${ }^{e}$ siècle de l'Hégire (VIII ${ }^{\mathrm{e}}$ siècle de notre ère). La plupart des hadiths ne commencent à se ramifier que durant cette période, et les hadiths possiblement plus anciens se ramifient alors de nouveau (les partial common links, PCL, c'est-à-dire les plus récents transmetteurs communs de second degré, dans la terminologie de Juynboll). Au cours de cette évolution, le nom du Mecquois 'Amr b. Šu'aib (mort en 736 ${ }^{134}$ ) apparait à plusieurs reprises, comme CL (plus récent transmetteur commun), ou bien comme PCL (plus récent transmetteur commun de second degré. ${ }^{135} \mathrm{Il}$ est l'arrière-petit-fils de 'Abdallāh b. 'Amr, qui a hérité de sa șạîfa et auquel on reprochait de l'avoir seulement " trouvé » en l'état et de ne pas l'avoir « entendu » de son père ${ }^{136}$.

Tandis que les spécialistes musulmans associent l'apprentissage par cœur aux Irakiens, et en particulier aux Bassoriens, l'emploi de șahîfa-s «trouvées »- que les adversaires de la mise par écrit rejettent bien sûr vigoureusement - sont mises en relation avec la «Syrie ${ }^{137}$ ou avec « La Mecque et le Yémen » ${ }^{138}$.

80 À La Mecque, Muğāhid (mort en $722^{139}$ ) était, parmi d'autres, l'un des partisans de l'écriture du Hadith. Il aurait confié ses "livres" à ses élèves pour qu'ils les recopient ${ }^{140}$. Une génération plus tard, le Mecquois Ibn Ğuraiğ (mort en $767^{141}$ ), qui passe, à l'instar de Sa'īd b. Abī 'Arūba, pour l'un des premiers auteurs de mușannaf-s (collections divisées en chapitres systématiques) ${ }^{142}$, s'enorgueillit ainsi : « Personne n'a autant compilé par écrit la tradition que moi » (mā dawwana al-'ilm tadwinī aḥad $)^{143}$ - et ce à peu près à la même époque où $S a$ 'îd $b$. Abī 'Arūba, à Bassora, se félicite de ne posséder aucun livre.

81 Il y avait certes à La Mecque des opposants à la mise par écrit, et les tenants de cette position ne formaient nullement, dans cette ville, un front presque uni, comme ce fut longtemps le cas des partisans de l'oralité à Bassora. Le plus célèbre Mecquois qui défendit la position d'une conservation de la tradition fondée sur l'oralité est 'Amr $b$. Dīnār (mort en 743). 'Alī b. al-Madīnī le compte parmi les six plus éminents "gardiens ( huffāz) du Hadith» de la communauté réunie autour de Mahomet (parmi les cinq autres figurent deux Bassoriens, deux Koufiens et le Médinois az-Zuhrī !) ${ }^{144}$. Toujours est-il que 'Amr b. Dīnār aurait autorisé son élève Sufyān b. 'Uyaina à noter des ațāf (« pointes / extrémités $")^{145}$.

C'est au Yémen que l'opposition contre la mise par écrit des traditions semble avoir été la moins importante. Le Yéménite Hammām b. Munabbih (mort en $719^{146}$ ) est l'auteur d'une șahifia (feuillet), qui est préservée dans une version ultérieure. Hammām aurait acheté «les livres ${ }^{147}$ pour son frère Wahb ${ }^{148}$ - tellement tous deux n'accordaient que peu de valeur à la tradition « par audition ». À travers l'exemple de Ma'mar b. Rāšĩd, un 
élève de Hammām b. Munabbih, nous avons vu que, au Yémen, on ne récitait pas par cœur (supra § 20).

Comment ce constat s'insère-t-il dans le tableau que nous avons dressé jusqu'à présent ? Tout d'abord, il ressort que, dans des centres plus éloignés de Damas comme La Mecque ou Sanaa, l'opposition à la codification du Hadith était plus faible qu'en Irak ou qu'à Médine. À La Mecque ou au Yémen, l'usage public de șahîfa-s semble déjà s'inscrire dans une certaine tradition. Si 'Abdallāh b. 'Amr b. al- 'Āṣ a déjà effectivement répandu le hadith dont il est question plus haut (III 1), il est logique d'interpréter sa position comme le fait d'une opposition, déjà isolée au I ${ }^{\text {er }}$ siècle de l'Hégire (VII ${ }^{e}$ siècle de notre ère), contre le consensus accepté de manière générale à cette époque, en vertu duquel le Hadith devait être considéré comme un enseignement oral - que l'on pouvait tout au plus noter sous la forme d'hypomnēmata, conservés aussi secrets que possible.

Quant à l'apologie de la mise par écrit fondée sur certains hadiths, développée au II siècle de l'Hégire (VIII ${ }^{e}$ siècle de notre ère), elle semble constituer moins un soutien aux efforts de codification initiés par les Omeyyades qu'une réaction - du moins en partie - à l'hostilité irako-médinoise envers l'écrit. Parmi les protagonistes s'illustrent notamment les possesseurs de notes, qui - comme dans le cas de 'Amr b. Šu'aib regardaient leurs șahiffa comme de précieux objets de famille et qui, pour cette raison, préconisaient de conserver la Tradition au moyen de l'écrit. Cette position pouvait ensuite provoquer à son tour une nouvelle réaction de la part d'un Bassorien, comme nous l'avons vu dans le cas d'Ibn 'Ulayya (supra $\$ 72$ et suiv.).

En ce II ${ }^{\mathrm{e}}$ siècle (VIII ${ }^{\mathrm{e}}$ siècle de notre ère), les partisans de la mise par écrit semblent ne pas pouvoir être rattachés à une orientation «idéologique " particulière. Il dut s'agir plutôt, en ce qui les concerne, de personnages pragmatiques, qui, parce qu'ils possédaient justement une précieuse șahiifa, parce qu'ils ne jouissaient pas d'une bonne mémoire, ou bien pour tout autre motif, n'étaient pas disposés à jouer le jeu de la transmission par cœur de la tradition. Par cette attitude, ils sont les devanciers d'un Aḥmad $b$. Hanbal, qui a souligné à plusieurs reprises le caractère problématique de cette méthode. Depuis le milieu du $\mathrm{II}^{\mathrm{e}}$ siècle (VIII ${ }^{\mathrm{e}}$ siècle de notre ère), on rencontre aussi parmi eux, de temps à autre, des Irakiens, qui - en tant que plus récents transmetteurs communs $(\mathrm{CL})$ - ont répandu des traditions favorables à la mise par écrit. Ainsi, le Bassorien al-Hașīb b. Ğahdar (mort en $763^{149}$ ) a mis en circulation ce hadith du Prophète d'après lequel ce dernier aurait dit à un homme qui se plaignait de sa mauvaise mémoire : "Soutiens ta mémoire de ta main droite " ${ }^{150}$. Les spécialistes musulmans ont déjà soupçonné al-Hुașib d'avoir fabriqué de toutes pièces ce hadith, et les critiques du Hadith le tiennent tous sans exception pour un menteur ${ }^{151}$. On peut parfaitement imaginer que sa prise de position -appuyée sur un hadith du Prophète en faveur de la mise par écrit des traditions dans la Bassora du II ${ }^{\mathrm{e}}$ siècle de l'Hégire (VIII ${ }^{e}$ siècle de notre ère), qui était hostile à cette pratique, ait contribué à lui valoir cette réputation.

Dans cinq hadiths apparaît le matn (texte) « enchaînez le Savoir » (qaiyidū al-'ilm), c'està-dire "fixez par écrit la Tradition ». Le slogan est attribué au Prophète ${ }^{152}$, à 'Alīi ${ }^{153}$, à 'Abdallāh ibn 'Abbās ${ }^{154}$, à Anas b. Malik ${ }^{155}$ et même à 'Umar' ${ }^{156}$. Que la Tradition, en fin de compte, devait être effectivement "enchaînée " c'est ce que montre l'évolution ultérieure, au III ${ }^{\mathrm{e}}$ siècle de l'Hégire (IX ${ }^{\mathrm{e}}$ siècle de notre ère). Comme dans le judaïsme, l'enseignement oral devint aussi, au sein de l'Islam, un second enseignement écrit, dont le prestige n'avait que peu ou rien à envier au premier ${ }^{157}$. 
87 Pourtant, on ne saurait prétendre que les tenants d'une Tradition écrite ont complètement triomphé de leurs adversaires. En effet, on ne renonça pas, au III $^{\mathrm{e}}$ siècle de l'Hégire et même plus tard, à une dimension de l'oralité longtemps requise : l'idéal d'une Tradition "par audition" $(\operatorname{sam} \bar{a})$, au cours de la leçon du maître. Comme auparavant, une tradition «purement recopiée» (kitāb[a]) ou "trouvé » était considérée comme "faible » et comme devant être évitée autant que possible (cf. la discussion sur la șahîfa de 'Amr b. Šu'aib, à laquelle ont également pris part, entre autres, Yahyā b. Ma'īn et 'Alī b. al-Madīnīi ${ }^{158}$ ). En principe, on devait même accéder, dans la mesure du possible, aux collections de traditions canoniques, les Șahîh-s (« Authentiques ») d'al-BuHāāī, Muslim, etc., à travers le sama $\bar{a}^{c 159}$, même si, en pratique, seuls quelques-uns parvinrent à entendre l'intégralité de ces œuvres colossales dans le cadre de lectures données par leurs auteurs ou par des transmetteurs autorisés ${ }^{160}$.

\section{Les diagrammes}

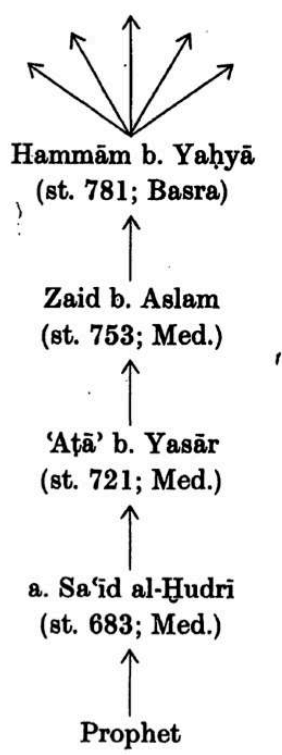

I.1 : « N'écrivez pas mes paroles, à l'exception du Coran » (Taqyüd, p. 29-32). 


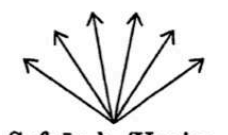

Sufyān b. Uyaina

(st. 812; Kufa, Mekka)

$\uparrow$

Zaid b. Aslam

$\uparrow$.

‘Atāa' b. Yasār

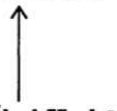

a. Sa ïd al-Hudri

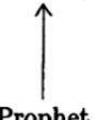

Prophet

I.2 : Le Prophète ne me l'a pas permis (Taquĩd, p. 32-33)

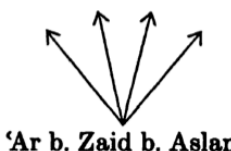

'Ar b. Zaid b. Aslam

(st. 798; Medina)

Zaid b. Aslam

$\prod_{\text {'Aț̄a' b. Yasār }}$

$: \uparrow$

a. Huraira

(st. 678; Med.)

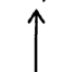

Prophet

I.3 : « Souhaitez-vous un autre livre que le livre de Dieu ? » (Taqyid, p. 33-35). 


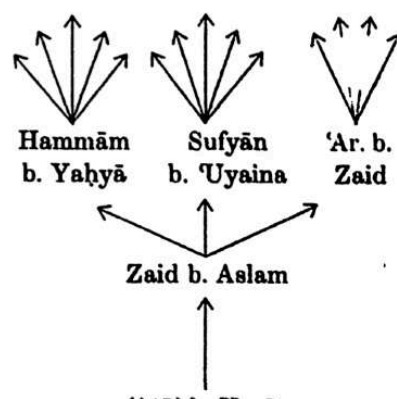

'Atāe' b. Yasār

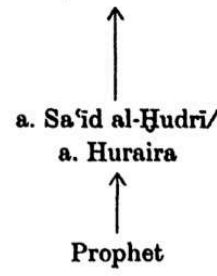

I.1/2/3 (Taquìd, p. 29-35).

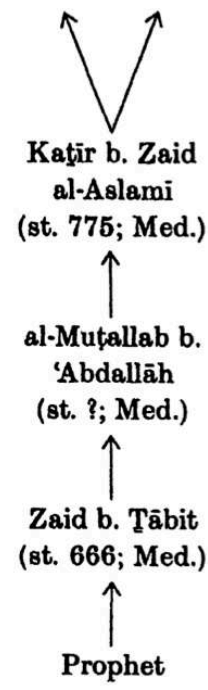

I.4 : Le Prophète a interdit d'écrire sa parole (Taquīd, p. 35) 


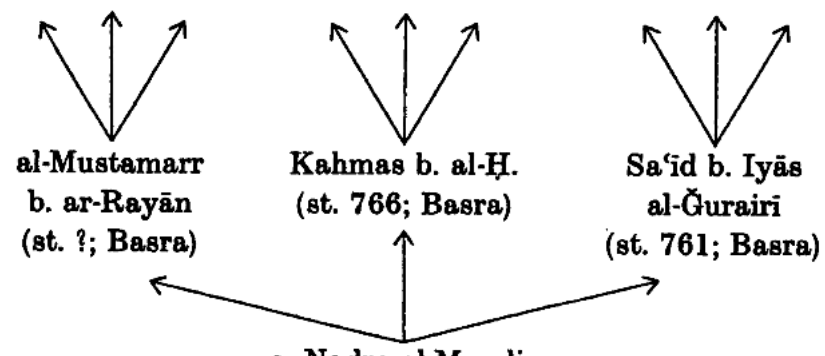

a. Nadra al-Mundir

b. Mālik

(st. um 727; Basra)

个

a. Sa'id al-Hudri

(st. 683; Med.)

II.1 : « Voulez-vous faire de cela des exemplaires du Coran ? " (Taqyīd, p. 36-38).

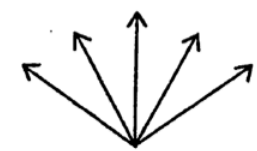

Ḥumaid b. Hilāl

(st. ?; Basra)

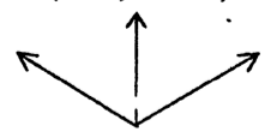

a. Burda b. a. Mūsā

(st. 722; Kufa)

a. Mūsā al-Ặ̛'ari

(st. 662; Kufa, Basra)

II.2 : « J'ai écrit d'après mon père de nombreux "livres" » (Taquïd, p. 39-41). 


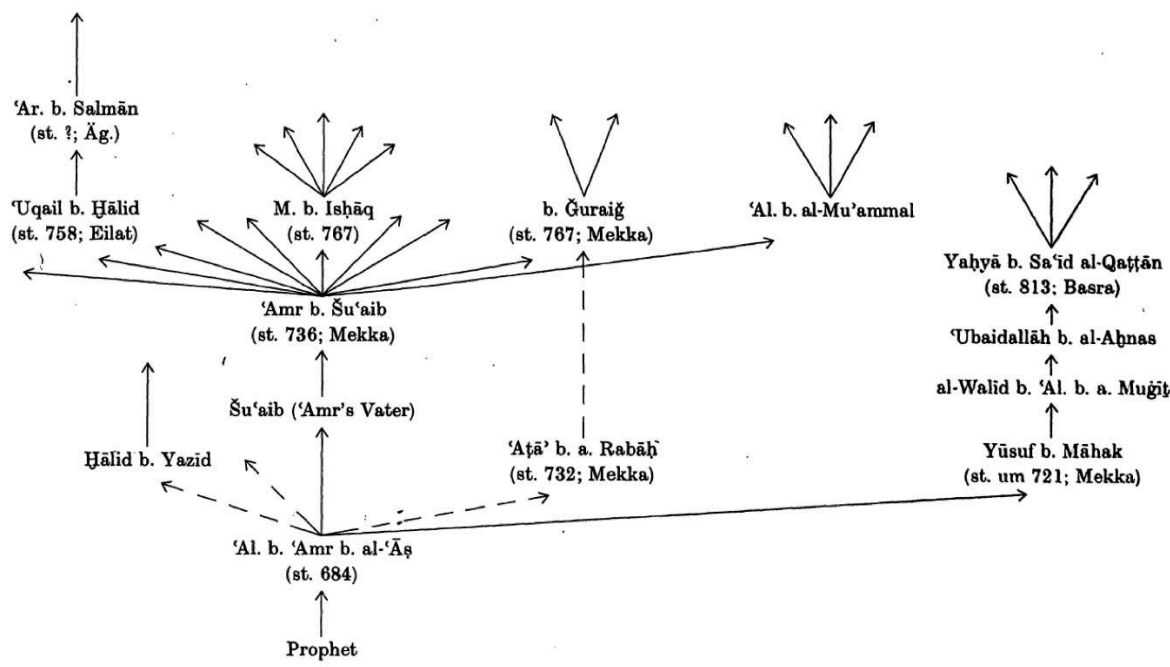

III.1 : « Oui, écrivez ! (Taquīd, p. 74-82).

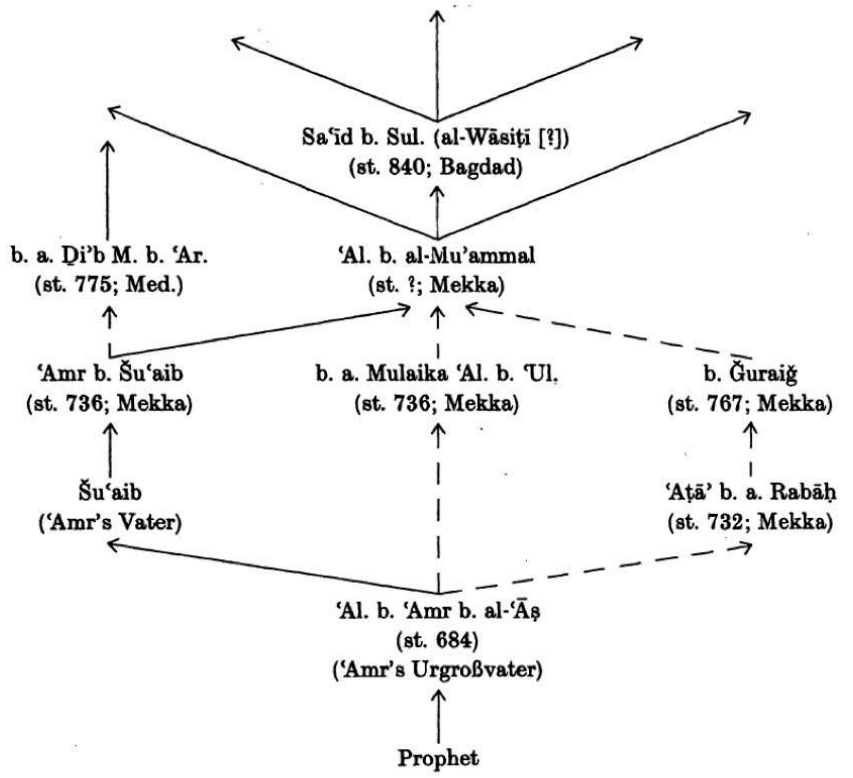

III.2 : « Enchaînez le Savoir ! » (Taqyīd, p. 68-69). 


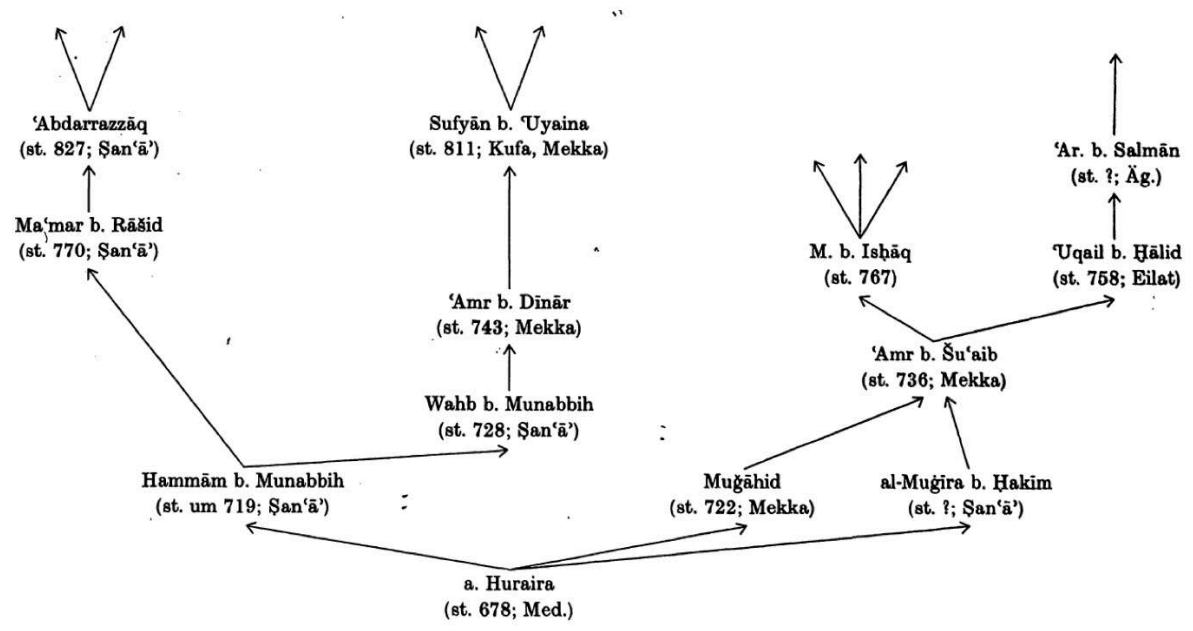

IV.1: « 'Abdallāh b. 'Amr avait coutume d'écrire... » (Taqyīd, p. 82-84).

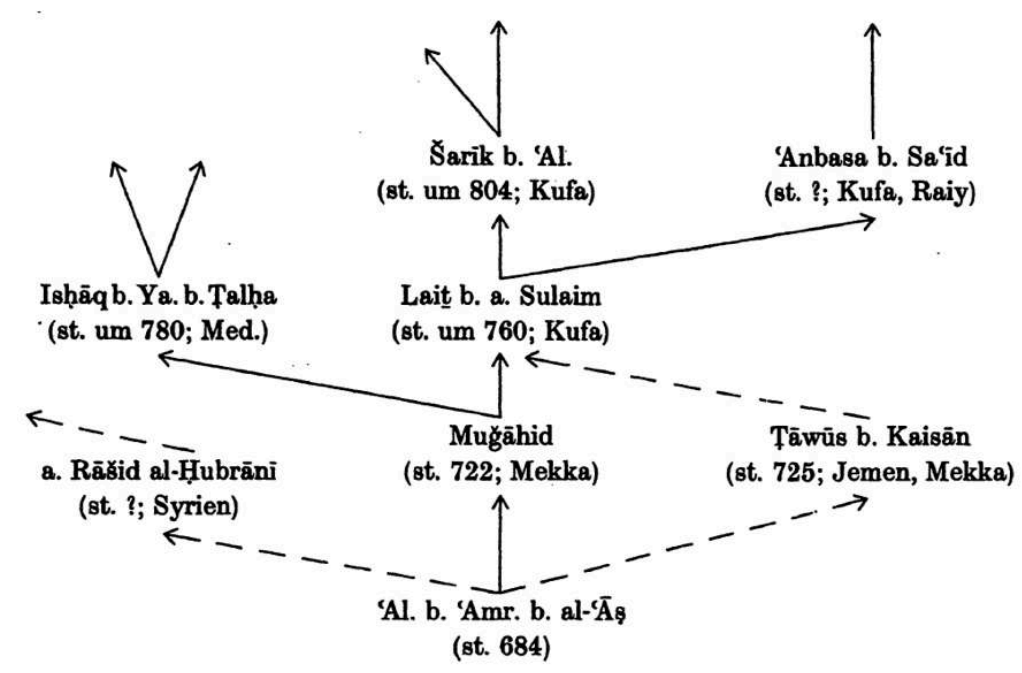

IV.2 : « Voici la sādiqa, voici ce que j'ai entendu du Prophète... » (Taqyīd, p. 84-85).

\section{Commentaires sur les diagrammes}

Les diagrammes ci-dessus décrivent les principaux isnād-s (chaînes de transmission) traités dans le présent travail d'après l'analyse de Schacht/Juynboll. Je désigne ainsi cette méthode d'analyse des isnād-s parce qu'elle a été formulée par Josef Schacht dans son livre intitulé The Origins of Muhammadan Jurisprudence ${ }^{161}$, avant d'être affinée et utilisée par G.H. A. Juynboll, dans le livre Muslim Tradition. Studies in Chronology, Provenance and Authorship of Early Hadīth ${ }^{162}$, ainsi que dans d'autres articles et 
conférences sur ce thème. Il convient toutefois de souligner que d'autres savants, comme Josef van Ess et Michael Cook, ont utilisé cette méthode de manière fructueuse et l'ont également en partie développée.

Dans cette méthode, le point de départ de l'analyse des isnād-s est un hadith particulier. Autant que possible, tous les isnād-s qui ont été conservés pour ce hadith sont collectés, comparés et représentés sur un diagramme. D'après le mode de représentation adopté par Juynboll, le Prophète, le transmetteur originel ou le transmetteur le plus ancien est placé au bas du diagramme, tandis que les transmetteurs ultérieurs sont disposés en ligne ascendante. Les flèches indiquent la direction dans laquelle le hadith est transmis. Les voies de transmission rarement attestées ou douteuses sont représentées par des flèches en pointillés. Dans le cas des hadiths du Prophète, il apparaît ainsi souvent que les trois ou quatre plus anciens transmetteurs après le Prophète sont identiques dans les isnād-s et que l'isnād se ramifie ensuite. Dans le mode de représentation que nous avons retenu, ces diagrammes décrivent dans une certaine mesure la forme d'un arbre. Dans le cas des hadiths des compagnons, l'isnād se ramifie souvent plus tôt. Schacht et Juynboll désignent du nom de common link (CL) le transmetteur au niveau duquel l'isnād se ramifie, c'est-à-dire le plus récent transmetteur commun. Le CL marque selon Schacht le moment à partir duquel la tradition fut au plus tôt diffusée. Juynboll appelle partial common links (PCL) les ramifications ultérieures (dans l'arborescence) de l'isnād. Ils sont responsables de la propagation et éventuellement de la reformulation d'une tradition.

\section{À propos de I et II}

90 Aucun des hadiths du Prophète I 1 à I 4 hostiles à la mise par écrit - il s'agit de tous ceux qui existent - n'apparaît dans les collections de traditions pré-canoniques (dorénavant désignées comme les collections « anciennes») suivantes, qui comportent un chapitre Fī karāhiyat kitāb al- 'ilm («A propos de l'aversion contre la fixation du Hadith au moyen de l'écriture») ou autres semblables : le K. al-Ğāmi' de Ma'mar b. Rāšīd (mort en 770), le K. al-'Ilm d'Abū Haițama (mort en 848) et le Muṣannaf de Ibn Abī Šaiba (mort en 849). Al-BuHārī (mort en 870) n'en invoque lui aussi aucun. À l'inverse, Muslim (mort en 875 ) connaît déjà I $1^{163}$, tandis qu'Abū Dawūd (mort en 888) et at-Tirmidīi (mort en 892) connaissent respectivement I $4^{164}$ et I 1 et I $2^{165}$. (Les autres collections canoniques n'ont pas été consultées). Nous avons établi plus haut que I 1, I 2 et I 3 sont des variantes d'un seul et même hadith. At-Tirmidīi (op. cit.) l'avait déjà remarqué et énoncé expressis verbis pour I 1 et I 2. Ad-Dahabī semble l'avoir remarqué pour I 2 et I 3. Dans son chapitre du Mizāan dédié à 'Abdarraḥmān b. Zaid b. Aslam ${ }^{166}$, où il s'appuie sur plusieurs des hadiths répandus par celui-ci, il mentionne en effet tout d'abord I 2, pour lequel il cite - correctement - Ibn 'Uyaina (CL dans I 2 !) comme plus récent transmetteur commun, et invoque dans la foulée I 3 (CL : 'Abdarraḥmān b. Zaid), qu'il qualifie de munkar (« rejeté », non reconnu). Ad-Dahabī a ainsi perçu, semble-t-il, le phénomène du $[\mathrm{P}] \mathrm{CL}$ !

91 Cependant, le hadith $\mathrm{I} 1 / 2 / 3$ en question n'est pas, à proprement parler, une falsification pure et simple, mais constitue davantage la "projection" ( $r a f^{f}$, littéralement "élévation ») d'une parole attribuée à Abū Sa'īd al-Hुudrī (peut-être authentique, mais en tout cas ancienne) (II 1, cf. infra) sur le Prophète. C'est la conjecture que formulaient déjà des spécialistes musulmans à commencer par alBuHārīi ${ }^{167}$. En réalité, les deux hadiths présentent bien un contenu similaire, et la 
transposition a dû être d'autant plus aisée qu'Abū Sa īid se réfère déjà au Prophète dans II 1 ( " conservez donc (vous aussi) un souvenir de nous dans votre mémoire, comme nous avons conservé un souvenir de votre Prophète »). La référence à une pratique de Mahomet pouvait aisément devenir une citation d'une parole de celui-ci. Selon toute probabilité, la projection est à mettre au compte de Zaid b. Aslam (CL dans I 1/2/3). (Une alternative bien moins probable consisterait à l'imputer à 'Ațầ' b. Yasār, d'après lequel Zayd $b$. Aslam - réellement ou prétendument - transmet la tradition.) Il n'en demeure pas moins que les transmetteurs de Zaidb. Aslam (Hammām b. Yahyā, Ibn 'Uyaina et 'Abdarraḥmān b. Zaid) ont dû déjà recevoir de Zaid la tradition projetée sur le Prophète, étant donné qu'ils s'accordent sur ce point particulier (Zaid en tant que leur maître commun). La formulation propre à I 1 , I 2 et I 3 est imputable, respectivement, à Hammām b. Yahyyā, Sufyān b. 'Uyaina et 'Abdarraḥmān b. Zaid b. Aslam, en tant que PCL.

Parmi les trois versions du hadith, la version I 3, associée au «faux " transmetteur originel Abū Huraira, est la plus problématique. Comme nous l'avons indiqué plus haut, ad-Dahabī l'avait déjà qualifiée de «non reconnue " (munkar). Il convient de noter qu'Ahmad b. Ḥanbal, qui introduit le hadith dans son Musnad (compilation de hadiths organisées selon les transmetteurs) ${ }^{168}$, le mentionne dans le chapitre consacré à Abū Sa 'îd al-Hudrī, bien que le transmetteur originel, cité dans l'isnād, soit Abū Huraira et non Abū Sa 'îd al-Hudrī! (Dans deux œuvres ultérieures auxquelles je n'ai pas accès, le « vrai » transmetteur original, Abū Sa īd al-Hुudrī, serait nommé169). S'agissant de I 2, alHațîib al-Bag̉dādī produit (par mégarde ? contamination avec I 3 ?) l'isnād (à partir de $\mathrm{CL}$ ) Ibn 'Uyaina 'an (d'après) 'Abdarrahmān $b$. Zaid b. Aslam 'an abihi (d'après son père), etc. Je lis cependant, avec at-Tirmid̄i ${ }^{170}$ et ad-Dārimī1 ${ }^{171}$ : Ibn 'Uyaina 'an (d'après) Zaid b. Aslam, etc. (Zaid b. Aslam figure chez Ibn Ḥağar parmi les šaiH-s (maître) d'Ibn 'Uyaina ${ }^{172}$; la chronologie ne pose pas de problème, puisque Ibn 'Uyaina [né en 725] avait 28 ans à la mort de Zaid [en 753].)

Dans le cas de I 4, il semble qu'il s'agisse également d'une projection - en l'occurrence de l'opinion de Zaid $b$. Tâait - sur le Prophète. Il existe en effet une tradition attribuée à Zaid lui-même qui est similaire (mais associée à un autre isnād), dans laquelle celui-ci, dans une situation semblable, refuse que ses propres paroles soient notées ${ }^{173}$. Selon toute vraisemblance, cette projection est à mettre au compte du Médinois Katīir b. Zaid al-Aslamī (CL). Une nouvelle fois, ad-Dahabī, qui cite cette tradition dans le chapitre du Mizāan $n^{174}$ qu'il consacre à Katīir b. Zaid, avait déjà remarqué que c'est ce dernier qui l'a transmise sous cette forme (c.-à-d. projetée sur le Prophète). Dans ce cas aussi, adDahabī a de toute évidence perçu le phénomène du CL !

Le hadith II 1 apparaît dans les deux collections « anciennes » d'Abū Huaitama ${ }^{175}$ et d'Ibn $A b \overline{~ S ̌ a i b a}{ }^{176}$. Il est peut-être authentique, et dans tous les cas ancien. Dans l'hypothèse où il ne remonterait pas à Abū Sa'îd al-Hुudrī, il a dû être associé à celui-ci au plus tard par le transmetteur suivant, le Bassorien Abū Naḍra (mort en 727), comme le montre de manière univoque le diagramme (Naḍra est clairement un CL, avec trois PCL !).

$\mathrm{Au}$ demeurant, un troisième hadith dirigé contre l'écrit, associé à un autre isnād, est

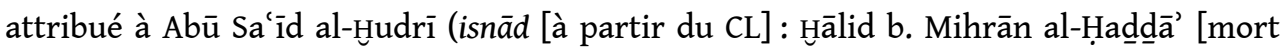
vers 758; Bassora] 'an (d'après) Abū al-Mutawakkil 'Alī b. Dāwūd [mort vers 720; Bassora] 'an (d'après) Abū Sa'îd al-Hudrī: "Nous avions coutume de ne rien écrire hormis le Coran et le tašahhud. ») ${ }^{177}$. Il est ainsi tout à fait possible que ce soit lui, et non 
Abū Naḍra, qui ait d'abord propagé la théorie selon laquelle il ne fallait pas noter les traditions.

Le hadith II 2 - tout comme II 1 - figure dans les deux collections « anciennes » d'Abū Haitama ${ }^{178}$ et d'Ibn Abí Šaiba ${ }^{179}$. Comme II 1, il fait partie des hadiths hostiles à la mise par écrit des traditions les plus fréquemment cités et les plus importants. Il est lui aussi peut-être authentique, et dans tous les cas anciens. Dans l'hypothèse où il ne remonterait pas à Abū Mūsā al-Aš̌rarī, il a dû être attribué à ce dernier par son fils Abū Burda (à Koufa), comme le montre une nouvelle fois le diagramme (Abū Burda comme $\mathrm{CL}$, avec des PCL).

Comme résultat positif de notre analyse des hadiths hostiles à la mise par écrit des traditions, nous pouvons établir que: (1) le Prophète, selon toute vraisemblance, n'a pas exprimé une telle opinion; (2) il n'est pas exclu que certains compagnons médinois aient prononcé cette interdiction dès le I ${ }^{\text {er }}$ siècle (VII ${ }^{e}$ siècle de notre ère); (3) il est certain que cette interdiction a été soutenue au sein de la première génération de successeurs (premier quart du $\mathrm{II}^{\mathrm{e}}$ siècle [ $\mathrm{VIII}^{\mathrm{e}}$ siècle de notre ère]), notamment à Bassora et à Koufa ; (4) elle fut projetée sur le Prophète au sein de la seconde génération de successeurs (deuxième quart du VIII ${ }^{\mathrm{e}}$ siècle), à Médine.

\section{À propos de III et IV}

98 Parmi les hadiths favorables à la mise par écrit évoqués ici, les suivants apparaissent dans les collections « anciennes » : III 1 figure dans le Muṣannaf d'Ibn Abī Šaiba ${ }^{180}$, tandis que IV 1 figure dans le Ğāmi' de Ma'mar b. Rāšìd ${ }^{181}$. Dans les quatre collections canoniques consultées, III 1 apparaît chez Abū Dāwūd ${ }^{182}$, alors que IV 1 est présent chez al-BuHāāi $1^{183}$ et chez at-Tirmidīi ${ }^{184}$.

99 Selon un autre hadith, le Prophète aurait autorisé un certain Abū Šāh, dans un cas précis, à faire noter pour lui-même une Huṭba (un prône) (transmetteur originel prétendu : Abū Huraira ; CL: Yahyā b. Abī Katīir ; mort en 749. Ce hadith figure dans les collections canoniques d'al-BuHā̄īi, d'Abū Dāwūd et d'at-Tirmidîi ${ }^{185}$. Cette tradition, qui n'apparaît dans aucune des collections "anciennes ", est tenue pour authentique par les critiques musulmans modernes ${ }^{186}$.

100 Tandis que les isnād-s des hadiths dans lesquels l'écrit est prohibé présentent tous l'arborescence habituelle (pour les hadiths du Prophète: Prophète - compagnon successeur [- successeur] - CL; pour les hadiths des compagnons abordés ici: compagnon - successeur $=\mathrm{CL}$ ), la structure des isnād-s des hadiths dans lesquels la mise par écrit est autorisée est plus difficile à apprécier. Pas un seul ne revêt, du moins à première vue, la forme d'un arbre. Par l'interprétation, toutefois, il est peut-être possible de la retrouver pour III 1, III 2 et IV 2.

III 1 s'approche de cette forme. En tous cas, cette tradition possède un CL très clairement identifiable, associé à plusieurs PCLs et placé dans la position habituelle : 'Amr b. Šu'aib. Il est ainsi certain que 'Amr b. Šu'aib a diffusé ce hadith. Pourtant, 'Abdallāh b. 'Amr, le transmetteur originel, pourrait très bien l'avoir lui-même propagé, dans la mesure où l'isnād se ramifie déjà à partir de lui. Toutefois, il est vrai que la plupart des autres lignes qui, partant de 'Abdallāh b. 'Amr, ne conduisent pas à 'Amr b. Šu'aib, ne sont que rarement transmises et conduisent en partie à des personnages obscurs, de sorte qu'on peut les écarter comme inauthentiques. Cependant, il n'en va pas nécessairement ainsi de la ligne Yūsuf b. Māhak 'an (d'après) 
'Abdallāh b. 'Amr, avec Sa'īd al-Qațtān comme CL (ou PCL). Elle figure chez Ibn Abī Šaiba et chez Abū Dāwū $d^{187}$. Il me paraît peu probable (mais cette hypothèse n'est pas à exclure) que Yahyā b. Sa īid al-Qatțān (en tant que CL ou PCL) ait inventé cet isnād, pour disposer, à la place de l'isnād 'Amr b. Šu'aib 'an abihi (d'après son père) jugé "faible " (au motif qu'il repose sur une tradition « purement recopiée »), d'un « meilleur » isnād, reposant sur une tradition "transmise par audition ». À cette hypothèse s'oppose en effet le fait qu'il s'agit d'une tradition dont le contenu n'a pas dû être particulièrement du goût de Yahyāa un savant bassorien qui se méfiait de l'écrit. Il n'est donc guère imaginable qu'il ait associé au hadith un "meilleur » isnād, qu'il aurait lui-même forgé de toutes pièces. Je considère que l'hypothèse suivante est plus probable. 'Ubaidallāh $b$. al-AHnnas, le šaih (maître) de Yahyā qui prétend de son côté tenir le hadith de al-Walīd b. 'Abdallāh b. Abī Muğīit ${ }^{188}$, était aussi un élève de 'Amr b. Šu'aib ${ }^{189}$. Les spécialistes musulmans lui attribuent déjà de nombreuses erreurs dans la transmission ${ }^{190}$. Pour cette raison, dans le cas de ce hadith, il est tout fait imaginable qu'en lieu et place du véritable transmetteur, 'Amr b. Šu'aib, il ait cité Walīd b. 'Abdallāh, un autre de ses maitres. Si c'est réellement le cas, nous aurions alors presque retrouvé l'arborescence. Nous n'aurions plus alors qu'à supprimer la ligne Ibn Ğuraiğ 'an (d'après) 'Ațầ' b. a. Rabāh, qui est rarement reprise et repose exclusivement, semble-t-il, sur le témoignage d'Ibn Ğuraiğ. Cette ligne est de toute façon moins digne de foi que la ligne Ibn Ğuraiğ 'an 'Amr b. Šu'aib, bien établie et attestée avec certitude sur le plan historique. Si l'on veut suivre ce raisonnement et admettre que 'Amr b. Šu'aib, en tant que CL, a été le premier à diffuser le hadith, il conviendrait de plus de se demander si, en associant le hadith à l'isnad " d'après mon père, qui le tenait de son grand-père " (isnad qui ne peut être vérifié) 'Amr a projeté sur le Prophète une tradition attribuée à l'origine à son arrière-grand-père 'Abdallāh $b$. 'Amr. Cette tradition pourrait être IV I que 'Amr b. Šu'aib possédait dans son répertoire. Nous serions alors en présence d'une situation tout à fait similaire que pour le hadith I $1 / 2 / 3$, très certainement dérivé de II 1 !) Le fait que 'Amr $b$. Šu'aib préfère généralement se référer au Prophète en tant que source du droit ${ }^{191}$ pourrait plaider en faveur de cette possibilité.

Pour terminer, il convient une nouvelle fois de rappeler que toutes ces considérations ne sont qu'hypothétiques et qu'on ne saurait exclure, en se fondant sur l'analyse de l' isnād, que le hadith ait été diffusé dès le $\mathrm{II}^{\mathrm{e}}$ siècle (VII ${ }^{\mathrm{e}}$ siècle de notre ère) par 'Abdallāh b. 'Amr.

103 Concernant le hadith III 2, des éléments plus positifs peuvent être formulés. Le texte n'est rien d'autre qu'une variante, en l'occurrence une actualisation de la formulation de III 1. Cette actualisation est à mettre au compte de 'Abdallāh b. al-Mu'ammal, qui tient la tradition de 'Amr b. Šu'aib (cf. également III 1 !). Il a simplement remplacé l'ancienne formulation, «Oui, écrivez!", par le slogan (voir supra § 86) «enchaînez le Savoir ». Il ne s'agit donc pas à proprement parler d'une falsification, mais d'une forme particulière de riwāya bil-ma'na (transmission selon le sens). Les deux lignes conduisant à 'Abdallāh b. 'Amr qui ne passent pas par 'Amr b. Šu'aib sont douteuses. Pour la ligne Ibn Ğuraiğ 'an (d'après) 'Ațâ̄' b. a. Rabāh 'an (d'après) 'Abdallāh b. 'Amr, cf. supra (\$ 101) à propos de III 1. La ligne Ibn Abī Mulaika 'an (d'après) 'Abdallāh b. 'Amr repose exclusivement sur le témoignage d'Ibn al-Mu'ammal et n'est très probablement pas authentique. Peut-être Ibn al-Mu' ammal a-t-il voulu appuyer sa version actualisée au moyen de ces isnād-s supplémentaires. Si notre raisonnement est exact - c'est en l'occurrence très probable -, nous aurions alors rétabli ici aussi, pour ce hadith, 
l'arborescence habituelle (avec 'Amr b. Šu'aib comme CL et 'Abdallāh b. al-Mu'ammal comme PCL).

Parmi les deux hadiths de compagnons abordés ici dans lesquels l'écrit est approuvé, IV 1 est dans tous les cas ancien. Il apparaît dans le Ğāmi' de Ma'mar ${ }^{192}$. Ce dernier tient cette tradition directement de son maître Hammām b. Munabbih. Si elle ne provient pas d'Abū Huraira elle a dû déjà lui être attribuée une génération plus tard. Elle possède, comme le montre le diagramme, deux CL-s (ou PCL-s, si l'on est enclin à reconnaître le transmetteur original prétendu comme CL): Hammām b. Munabbih, ainsi que 'Amr b. Šu'aib. Ce dernier reçoit cette tradition d' Abū Huraira, par l'entremise de deux maîtres, Muğāhid et al-Mugìira b. Ḥakīm.

Dans IV 2, Muğāhid est clairement CL (avec deux PCL-s). Il a ainsi dû propager le hadith au début du IIe siècle (VIII ${ }^{e}$ siècle de notre ére), voire plus tôt. Les autres lignes issues $\mathrm{du}$ transmetteur originel (présumé), 'Abdallāh b. 'Amr, sont rarement attestées (comme Abū Rāšid al-Ḥubrānī 'an (d'après) 'Abdallāh b. 'Amr), ou bien reposent exclusivement sur le témoignage d'un seul transmetteur (ainsi Lait 'an Ṭāwūs 'an 'Abdallāh b. 'Amr ; Ṭāwūs n'est mentionné comme témoin que par Lait, qui tient aussi ce hadith de Muǧāhid, selon une tradition plus sûre).

En résumé et pour conclure, on peut établir les éléments suivants. Il est certain que, dès le début du $\mathrm{II}^{\mathrm{e}}$ siècle (VIII ${ }^{\mathrm{e}}$ siècle de notre ère), on a attribué des traditions favorables à la mise par écrit aux compagnons Abū Huraira et 'Abdallāh b. 'Amr (IV 1, IV 2). Il est possible que ces traditions remontent effectivement à ces deux compagnons. Dans ce cas, elles auraient été diffusées dès le $\mathrm{I}^{\mathrm{er}}$ siècle (VII siècle de notre ère). Les hadiths $d u$ Prophète dans lesquels l'écriture est autorisée sont probablement plus récents que les hadiths des compagnons correspondants (transmis d'abord par 'Amr b. Šu'aib, mort en 736, qui est clairement CL dans III 1/2). Ils sont cependant plus anciens - le fait est certain - que les hadiths du Prophète proscrivant l'écriture (dans lesquels Zaid $b$. Aslam, mort en 753 , est $\mathrm{CL}$ ). Néanmoins, il n'est pas totalement exclu que, dès le $\mathrm{I}^{\text {er }}$ siècle (VII ${ }^{\mathrm{e}}$ siècle de notre ère), un hadith du Prophète favorable à la mise par écrit ait été diffusé ('Abdallāh b. 'Amr, mort en 884, comme possible CL in III 1/2).

Il s'ensuit donc la possible chronologie suivante (nous laissons ici de côté le I ${ }^{\text {er }}$ siècle (VII ${ }^{e}$ siècle de notre ère), durant lequel il y eut peut-être déjà une discussion mineure sur ce thème) :

1) Des successeurs attribuent à certains compagnons des hadiths favorables à une transmission par écrit (premier quart du Ier siècle (VII ${ }^{e}$ siècle de notre ère), notamment à La Mecque et au Yémen), dans un premier temps probablement en réaction au consensus (théorique), largement accepté, en vertu duquel les traditions ne doivent pas être mises par écrit (pour un usage public), mais aussi, très vite, en opposition à 2).

2) Durant la même période, d'autres successeurs attribuent à certains compagnons des hadiths hostiles à une transmission écrite (à Bassora, à Koufa, mais aussi à La Mecque), dans un premier temps probablement en réaction à la pratique, de plus en plus répandue, qui consiste à mettre par écrit des traditions afin de soutenir la mémoire, mais aussi, très vite, dans une discussion avec 1 ) et - avant toute chose - en réaction aux velléités de codification des Omeyyades.

3) Hadiths du Prophète favorables à l'écriture (premier et deuxième quart du $\mathrm{II}^{\mathrm{e}}$ siècle (VIII ${ }^{e}$ siècle de notre ère), notamment à La Mecque), en réaction à 2 ).

4) Hadiths du Prophète hostiles à l'écriture (deuxième et troisième quart du II ${ }^{e}$ siècle (VIII ${ }^{\mathrm{e}}$ siècle de notre ère), à Médine et à Bassora), en réaction à 3 ), mais aussi, en 
particulier, à l'utilisation en public, de plus en plus répandue, de collections écrites dues à des spécialistes de la Tradition, notamment à Damas, à La Mecque et à Sanaa.

\section{Addenda}

(Ces ajouts sont tirés de la traduction anglaise de cet article, G. Schoeler: The Oral and the Written in Early Islam, trad. U. Vagelpohl, éd. par J. E. Montgomery, Londres : Routledge, 2006, p. 140-141)

Le plus important travail sur le sujet paru après mon article est une très longue contribution de Michael Cook: "The Opponents of the Writing of Tradition in Early Islam ${ }^{193}$. Quoique d'accord avec moi sur la plupart des points, il souligne toutefois quelques «désaccords substantiels ${ }^{194}$. Il écrit : «La différence majeure entre son approche méthodologique et la mienne est que Schoeler adhère à la méthode du “ common link" de Schacht ${ }^{195}$. En outre, Cook soutient que nous ne pouvons affirmer rien de certain quant à la controverse autour de la mise par écrit des traditions au premier/ septième siècle ${ }^{196}$. Notons cependant qu'il n'avance aucune objection sérieuse contre ma chronologie de cette controverse ${ }^{197}$.

109 Un autre point de discorde est mon récit des efforts des Omeyyades pour codifier le hadith ainsi que mon point de vue sur les activités d'az-Zuhrī en tant que collectionneur de traditions ${ }^{198}$. Sur la base des arguments exposés ci-dessus, je ne vois toujours aucune raison de douter de l'authenticité de ces récits. "La principale objection [de Cook] à ce point de vue est que, si ces initiatives avaient eu un fondement historique, traduisant un effort concerté de la part des autorités syriennes, nous aurions pu nous attendre à ce qu'elles laissent une forte empreinte sur la Tradition syrienne, ce qui n'est pas le cas ». L'auteur admet cependant que " ces récits... ne sont pas invraisemblables en soi $»^{199}$. Voir aussi mes remarques concernant les pages 122 et $123-124$.

110 Une autre importante contribution ultérieure sur la question est l'article de Meir J. Kister intitulé «Lā taqra'ū 'l-qur'āna 'alā 'l-mușhafiyyīn ... Some Notes on the Transmission of Hadìt $»^{200}$ dans lequel il énumère et analyse de nombreuses traditions traitant de la mise par écrit du hadith.

111 p. 122 et p. 123-124 [= § 62 et 63-67]

Selon toute vraisemblance, l'élément de coercition qui transparait dans la tradition d'az-Zuhrī « on éprouvait de l'aversion envers la mise par écrit... » se rapporte au calife Hišām et non à 'Umar II : dans les traditions qui se réfèrent à 'Umar II et qui traitent de la codification du hadith, un tel élément n'apparaît jamais ${ }^{201}$. Le peu de fois qu'il est fait mention d'un souverain exerçant de la pression, il ne s'agit pas de 'Umar II, mais toujours d'Hišām. Cook pense que les récits concernant la codification du hadith ont été transférés d'Hišām à 'Umar : " dans certaines versions... (le tyran ?) Hišām est remplacé par (le pieux ?) 'Umar ibn 'Abd al-'Azīz; la tradition n'a alors plus le caractère d'une excuse $~^{202}$. Il me semble que les traditions concernant les efforts de codification de 'Umar II ne mentionnaient à l'origine que le seul Abū Bakr ibn Muḥammad ibn 'Amr ibn Hazm comme collectionneur (désigné). Manifestement ce ne sont que des récits plus tardifs et peu fiables qui établissent un lien entre 'Umar II et az-Zuhrīi203. Ainsi, la compilation de hadiths d'az-Zuhrī - que je considère comme étant historique - n'a 
probablement été établie qu'à l'époque où Hišām était calife. Il l'a commandé à l'usage des princes.

Il semble en effet y avoir eu, après tout, une certaine opposition à la mise par écrit des traditions au Yémen dans la première moitié du deuxième/huitième siècle. Cook ${ }^{204}$ souligne que dans la plupart des sources, Ṭāwūs ibn Kaysān (mort en 106/724-725) est présenté comme étant opposé à l'écrit. Sur cette question, je m'aligne dorénavant sur Michael Cook qui note que «les deux traditions, yéménite comme mecquoise, apportent des preuves tangibles de la controverse sur la mise par écrit ${ }^{205}$. p. 139-140 [= § 106 et suiv.]

Michael Cook rejette la méthode du common link sur laquelle se fonde ma chronologie hypothétique de la controverse, mais il observe toutefois : "N'étant moi-même pas en mesure d'établir une telle chronologie, je n'y vois aucune objection sérieuse $»^{206}$.

\section{BIBLIOGRAPHIE}

Abbott 2 : Abbott, Nabia, Studies in Arabic Literary Papyri. II. Qur'ānic Commentary and Tradition, Chicago, 1967.

'Abdarrazzāq : ‘Abdarrazzāq b. Hammām aṣ-Ṣan'ānī, al-Mușannaf, Ḥabībarraḥmān al-A'ẓamī (éd.), vol. 1-11, réimp., Beyrouth, $1392 \mathrm{AH}=1972$ (en annexe : Ma'mar b. Rāšīd, Ǧāmi').

Abū Dāwūd : Sunan Abī Dāwūd, M. M. 'Abdalhạamīd (éd.), 3, Le Caire, ${ }^{2} 1369$ AH = 1950.

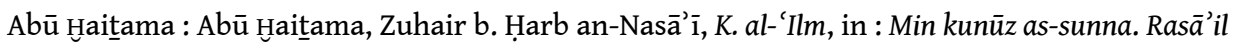
arba', M. Nāṣiraddīn al-Albānī (éd.), Damas, 1385 AH, p. 103-149.

Abū Nu'aim : Abū Nu'aim, Ahmad b. 'Abdallāh al-Iṣbahānī, Hilyat al-auliyā' wa-țabaqāt al-așfiyā', 1-10, Le Caire, 1932-1938.

Ad-Dārimī : Ad-Dārimī, 'Abdallāh b. 'Abdarraḥmān, Sunan, 'A. H. Yamānī al-Madanī (éd.), 1-2, Médine, 1966.

Brüll: Brüll, N., Jahrbücher für jüdische Geschichte und Literatur, vol. 2, Francfort-sur-le-Main, 1876.

Fatḥ : Ibn Ḥağar al-'Asqalānī, Šihābaddīn Aḥmad b. 'Alī, Fatḥ al-bāri bi-šarḥ Șahịḥ̣ al-BuHāāì, T. 'A. Sa'd, M. M. al-Hawārī (éd.), 1-28, Le Caire, 1978.

Ğāmi' : Ibn 'Abdalbarr, Yūsuf b. 'Abdallāh, Ǧāmi' bayān al-'ilm wa-mā yanbaġī fì riwāyatihī wahamalatihī, 1-2, Le Caire, sans date.

GAS : Sezgin, Fuat, Geschichte des arabischen Schrifttums, 1, Leyde, 1967.

Gerhardsson : Gerhardsson, Birger, Memory and Manuscript. Oral Tradition and Written Transmission in Rabbinic Judaism and Early Christianity, Uppsala, 1961.

Goldziher : Goldziher, I., « Ueber die Entwickelung des Hadith », in : Muhammedanische Ibn Abī Šaiba : Ibn Abī Šaiba, 'Abdallāh b. Muḥammad, al-Kitāb al-Muṣannaf, 'A. Hูān al-Afḡānī et al. (éd.), 1-15, Hyderabad - Bombay, 1966-1983. 
Ibn Qutaiba : Ibn Qutaiba, 'Abdallāh b. Muslim, K. Ta'wïl muHtalif al-ḥadīt, Le Caire, 1326 AH = 1908 . Ibn Sa'd : Ibn Sa'd, Muhammad, K. aț-Ṭabaqāt al-kabīr, 1-9, E. Sachau et al. (éd.), Leyde, 1904-1928. ‘Ilal : Ibn Ḥanbal, Aḥmad b. Muhammad, K. al-'Ilal wa-ma'rifat ar-riğāl, T. Koçyiǧit, I. Carrahoğlu (éd.), 1, Ankara, 1963.

JE : The Jewish Encyclopedia, 1-12, New York / Londres, 1907.

JNES : Journal of Near Eastern Studies.

JSAI : Jerusalem Studies in Arabic and Islam.

Juynboll : Juynboll, G. H. A., Muslim Tradition. Studies in Chronology, Provenance and Authorship of Early Hadìth, Cambridge / Londres, 1983.

Kaatz : Kaatz, S., Die mündliche Lehre und ihr Dogma, Leipzig, 1922.

Kaplan : Kaplan, Julius, The Redaction of the Babylonian Talmud, New York, 1933.

Kifāya : al-Hुațīb al-Bağdādī, Aḥmad b. 'Alī, K. al-Kifāya fì 'ilm ar-riwāya, Hyderabad, ${ }^{2} 1970$.

Lieberman : Lieberman, Saul, Hellenism in Jewish Palestine, New York, 1950.

Mağrūḥin : Ibn Ḥibbān al-Bustī, Muḥammad, al-Mağrūḥin min al-muhaddițin waḍ-ḍu 'afâa' walmātrūkīn, 'A. M. Zāyid (éd.), 1-3, Alep (?), ${ }^{2} 1402$ AH.

Ma'mar b. Rāšīd : voir 'Abdarrazzāq.

Mìzān : ad-Dahabī, Muhammad b. Aḥmad, Mīzān al-i'tidāl, 'A. M. al-Bağāwī (éd.), 1-4, Le Caire, 1963-1965.

Muslim : Șaḥiḥ Muslim bi-šarḥ an-Nawawī, 1-18, Beyrouth, ${ }^{2} 1392$ AH = 1972.

Musnad : Ibn Hanbal, Ahmad b. Muhammad, al-Musnad, 1-6, Le Caire, 1313 AH.

RGG : Die Religion in Geschichte und Gegenwart, $3^{\mathrm{e}}$ éd., Kurt Galling (éd.), vol. 1, Tübingen, 1957. Strack : Strack, Hermann L., Einleitung in Talmud und Midraš, Munich, ${ }^{5} 1921$.

Tadkira : ad-Dahabī, Muhammad b. Aḥmad, K. Tạdkira al-huffāz, 1-4, Hyderabad, 1955-1958.

Tahdīib : Ibn Ḥağar al-'Asqalānī, Šihābaddīn Aḥmad b. 'Alī, K. Tahdīib at-tahdīib, 1-14, Beyrouth, 1984-1985.

Taqyīd : al-Hुațīb al-Baġdādī, Ahmad b. 'Alī, Taqyīd al-'ilm, Y. Al-'Uš (éd.), Beyrouth (?), ${ }^{2} 1974$. Ta'rīH Bag̀dād : al-Hูațīb al-Bağdādī, Aḥmad b. 'Alī, Ta'rīH Bağdād au Madīnat as-salām, 1-14, Le Caire, 1931.

Tirmidī : at-Tirmidī, Muḥammad b. 'Īsā, Șaḥiḥ, 1-2, Boulaq, 1292 AH.

ZDMG : Zeitschrift der Deutschen Morgenländischen Gesellschaft.

\section{NOTES}

1. In : Der Islam 8 (1918), p. 44.

2. In : Muhammedanische Studien, vol. 2, Halle, 1890, p. 194.

3. In : ZDMG 10 (1856), p. 1-17.

4. Ibid., p. 5 et suiv.

5. Goldziher, in : Muh. Stud., p. 196.

6. Goldziher, ibid., p. 196. 
7. GAS 1, p. 53 et suiv.

8. Kaatz, p. 1.

9. Strack, p. 10 et suiv. ; Lieberman, p. 87 et suiv., p. 204 et suiv. ; Gerhardsson, p. 159 et suiv.

10. Strack, p. 14.

11. Lieberman, p. 87 et suiv.

12. Strack, p. 14.

13. Cf. RGG, vol.l, p. 113 et suiv., art. «Bibel II B. Sammlung und Kanonisierung des Neuen Testaments ».

14. En particulier p. 202, p. 335.

15. JE, vol. 12, p. 19 et suiv. ; s. v. Talmud ; Kifāya, p. 303, p. 344 et suiv.

16. Lieberman, p. 87, p. 204 ; Gerhardsson, p. 160 et suiv.

17. Taqyid, p. 109.

18. Dārimī, vol. 1, p. 100 ; Taqyìd, p. 48 ; Ǧāmi', vol. 1, p. 67 ; Abbott, vol. 2, p. 60.

19. Taqyìd, p. 46 ; Ğāmi', vol. 1, p. 67.

20. Taqyìd, p. 53 et suiv., p. 58 et suiv.

21. Taqyid, p. 61 et suiv.

22. Ibn Abī Šaiba, vol. 9, p. 51, nº 6484 ; Abū Hูaițama, p. 141, nº 135 ; Ğāmi', vol. 1, p. 62 ; Dārimī, vol. 1, p. 99.

23. Lieberman, p. 87 ; Gerhardsson, p. 161 ; Taqyìd, p. 100.

24. 'Ilal, p. 42, p. 50 ; Ibn Abī Šaiba, vol. 9, p. 51, nº 6489 ; cf. GAS, vol.1, p. 63.

25. Strack, p. 12.

26. Taqyìd, p. 136.

27. Strack, p. 14.

28. In : Der Islam 8 (1918), p. 46.

29. Juynboll, p. 17 et suiv.

30. Goldziher, in : Muh. Stud., p. 197.

31. Cf. N. Brüll, Jahrbücher für jüdische Geschichte und Literatur, vol. 2, 1876, p. 8.

32. Lieberman, p. 91 et suiv.

33. Lieberman, p. 96 et suiv.

34. Vol. 8, p. 614.

35. Cf. encore Strack, p. 18, p. 71.

36. Cf. l'article « Talmud», in :JE, vol. 12, p. 20.

37. Cf. Brüll, p. 18 et suiv.

38. 'Ilal, p. 348, Tahdīib, vol. 6, p. 358, s. v. «'Abdalmalik b. 'Abd al-'Azīz lbn Ğuraiğ »; Tadkira, p. 177.

39. Tadkira, p. 177 ; Tahdiib, vol. 4, p. 57.

40. Mìzān, vol. 4, p. 309 ; Tahdìib, vol. 11, p. 61.

41. Ibn Sa'd, vol. 7/II, p. 76 ; Tahdïib, vol. 6, p. 399.

42. Tahdīb, vol. 6, p. 279 ; s. v. « 'Abdarrazzāq b. Hammām ».

43. Tahdïb, vol. 11, p. 192.

44. Ta'rīh Bag̀dād, vol. 14, p. 140.

45. Tahdiib, vol. 11, p. 183 et suiv.

46. Tahdiib, vol. 11, p.112 ; cf. Der Islam 62 (1985), p. 207.

47. Voir par exemple Ibn Abī Šaiba, vol. 10, p. 154.

48. Tahdi ib, vol. 3, p. 254.

49. Tahdiib, vol. 4, p. 107.

50. Tahdib, vol. 6, p. 279.

51. Tahdib, vol. 10, p. 219

52. Ğāmī , vol. 1, p. 75.

53. Tadkira, p. 429 ; Tahdīb, vol. 11, p. 247 et suiv. 
54. Tahdib, vol. 11, p. 248.

55. Taqyìd, p. 29-32; cf. infra diagramme I 1.

56. Taqyìd, p. 33-35; cf. infra diagramme I 3.

57. Taqyìd, p. 36-38; cf. infra diagramme II 1.

58. Taqyìd, p. 46 et suiv.

59. Taqyīd, p. 65-68.

60. Taqyìd, p. 91

61. Taqyìd, p. 57 ; Ğāmī', vol. 1, p. 68 ; Fath, vol. 1, p. 315.

62. Pour Zaid: voir infra diagramme I 4 et nos commentaires; pour Abū Mūsā al-Aš́arī: diagramme II 2 et nos commentaires ; pour 'Abdallāh b. Mas' ūd : voir infra et Taqyīd, p. 38-39.

63. Taqyì, p. 57.

64. Taqyīd, p. 58 ; Ğāmī', vol. 1, p. 68 et suiv. ; Fath, vol. 1, p. 315.

65. Taqyid, p. 61 et p. 64 .

66. Taqyid, p. 61.

67. Ibn Qutaiba, p. 365 et suiv. ; Fath, vol. 1, p. 315.

68. Ibn Qutaiba, p. 366.

69. Fath, vol. 1, p. 315.

70. Ğāmī', vol. 1, p. 69 et suiv. ; Taqyìd, p. 64 et suiv.

71. Leyde, 1969, p. 47-61.

72. Cf. Abbott, p. 7 et GAS, vol. 1, p. 62.

73. In : ZDMG 61 (1907), p. 860-872.

74. Ibid., p. 862.

75. Ibid., p. 863 et suiv.

76. Ibid., p. 681.

77. Ibid., p. 862 et p. 865 .

78. Goldziher, in : Muh. Stud., p. 194 et suiv.

79. Le ra'y est la propre opinion juridique du spécialiste, non basée sur le Koran ou la Tradition.

80. Y. Al-'Uš, dans l'introduction au Taqyìd, p. 21 et suiv.

81. Cf. Kaplan, p. 265, p. 268.

82. Kaplan, p. 268.

83. Sur le point 1 qui vient d'être mentionné : cf. supra ( $(42)$, point 4 , ainsi qu'infra (§ 57), point 4 ; sur le point 2 ci-dessus, cf. supra ( $\$ 38$ et suiv.), points 1 et 2 .

84. Cf. Der Islam 62 (1985), p. 227 et suiv.

85. Kaplan, p. 265 ; Brüll, p. 3 et suiv. ; Kaatz, p. 2 ; Strack, p. 14 ; R. Bloch, in : Cahiers Sioniens 8 (1954), p. 13.

86. Ibn Sa'd, vol.3/I, p. 206 ; Taqyìd, p. 49-51; cf. Abbott, p. 7, avec des références à d'autres sources.

87. Ibn Sa'd, vol. 4/I, p. 13 et suiv. ; cf. Goldziher, in : ZDMG 61 (1907), p. 861.

88. Voir sur ce point Goldziher, ibid., p. 864 ; et enfin M. Cook, in : JSAI 9 (1987), p. 161-182.

89. Taqyid, p. 39.

90. Ibn Sa'd, vol. 5, p. 535.

91. Taqyìd, p. 64.

92. Kaplan, p. 265.

93. Ibn Sa'd, vol. 2/II, p. 134 ; Taqyìd, p. 105 et suiv. ; Ğāmī', vol. 1, p. 76 ; Dārimi, vol. 1/104 ; cf. Abbott, p. 25 et suiv. ; GAS, vol. 1, p. 281.

94. Taqyìd, p. 41 ; Ibn Sa'd, vol. 2/II, p. 117 ; Dārimi, vol. 1, p. 101.

95. Ibn Sa'd, vol. 7/II, p. 157 ; cf. GAS, vol. 1, p. 62 et suiv.

96. Ibn Sa'd, vol. 2/II, p. 134 ; GAS, vol. 1, p. 56 et suiv.; Abbott, p. 25 et suiv.

97. Ğāmī', vol. 1, p. 73, 76 ; Abū Nu'aim, vol. 3, p. 363 ; cf. GAS, vol. 1, p. 280. 
98. Ma'mar b. Rāšīd, chez 'Abdarrazzāq, vol. 11, p. 258, n 20486 ; Ibn Sa'd, vol. 2/II, p. 135 ; Taqyìd , p. 107 ; cf. GAS, vol. 1, p. 281, avec des références à d'autres sources.

99. Mìzān, vol. 3, p. 265 ; Tahdīib, vol. 8, p. 44 ; voir l'expression une nouvelle fois ibid., p. 48 ; ainsi que vol. 6, p. 360, s. v. 'Abdalmalik b. 'Abdal'aziz Ibn Ğuraiğ.

100. Taqyid, p. 57.

101. Miḥna (épreuve, examen) était une forme de tribunal inquisitional chargé du contrôle de l'orthodoxie religieuse, menant des persécutions contre les adversaires du Mu'talzisme, doctrine officielle du califat abbaside sous al-Ma'mūn (règne : 813-833). La Mihnna suscita l'opposition des milieux tradtionalistes, regroupés notamment autour d'Aḥmad b. Ḥanbal (cf. fr.wikipedia.org).

102. Mìzān, vol. 4, p. 410.

103. Ğāmī', vol. 1 , p. 66 ; Taqyìd, p. 59.

104. Dārimī, vol. 1, p. 100.

105. Ğāmī', vol. 1, p. 63 .

106. Tirmidīi, vol. 2, p. 111.

107. Goldziher, in : Muh. Stud., p. 210 et suiv.

108. 'Abdarrazzāq, vol. 11, p. 258, nº 20486.

109. 'Abdarrazzāq, vol. 11, p. 257-259.

110. Ma'mar b. Rāšīd, chez 'Abdarrazzāq, vol. 11, p. 258 et suiv. = ${ }^{\circ} 20487$; Ibn Sa'd, vol. 2/II, p. 135 ; Taqyìd, p. 107 ; Tadkira, p. 109 ; cf. J. Horovitz, in : Islamic Culture 2 (1928), p. 46-49.

111. Ğāmī', vol. 1 , p. 77 .

112. Abū Nu'aim, vol. 3, p. 363.

113. Taqyid, p. 108.

114. Tahdīib, vol. 10, p. 269 ; Mìzān, vol. 4, p. 181 et suiv.

115. Tahdib, vol. 12, p. 21 et suiv. ; Tadkira, p. 95.

116. Voir Taqyìd, p. 39-41; diagramme II 2.

117. GAS, vol. 1, p. 405 et suiv. ; diagrammes I 1, I 2 et I 3.

118. Tahdïb, vol. 3, p. 341.

119. 'Ilal, p. 55 ; Taqyìd, p. 79.

120. Tahdīib, vol. 1, p. 241 et suiv., s. v. Ismā'îl b. Ibrāhīm b. Miqsam.

121. Taqyìd, p. 74 et suiv. ; voir diagramme III 1.

122. GAS, vol. 1 , p. 31 et suiv.

123. Tahdiib, vol. 8, p. 318.

124. Tahdīib, vol. 11, p. 183 ; s. v. Yahyā b. Zakarīyā' Ibn Abī Zā'ida.

125. Tahdīib, vol. 4, p. 196 ; s. v. Sulaimān b. Mihrān.

126. J. Horovitz, in : Islamic Culture 2 (1928), p. 41 et suiv.; Goldziher, in : Muh. Stud., p. 38 et suiv.

127. Orientation théologique qui croyait au libre arbitre.

128. Voir notamment J. van Ess, Zwischen Hadīt und Theologie, Berlin / New York, 1975 et Early Muslim Dogma, Cambridge / Londres, 1981.

129. GAS, vol. 1, p. 84 .

130. Taqyìd, p. 74-82, diagramme III 1 ; Taqyìd, p. 68-69, diagramme III 2 ; Taqyìd, p. 84-85, diagramme IV 2.

131. Taqyï, p. 82-84, diagramme IV 1.

132. Taqyìd, p. 74-82, diagramme III 1 ; voir toutefois les commentaires sur les diagrammes III et IV infra!)

133. Taqyīd, p. 84-85; diagramme IV 2.

134. Tahdi ib, vol. 8, p. 43 et suiv.

135. Taqyìd, p. 74-82, diagramme III 1 ; Taqyìd, p.68-69, diagramme III 2 ; Taqyìd, p. 82-84, diagramme IV 1.

136. Tahdīb, vol. 8, p. 44 et suiv., en particulier p. 47 et suiv. ; Mīzān, vol. 3, p. 264 et suiv.; Ibn Qutaiba, p. 93. 
137. Taqyìd, p. 53, ligne 9 ; p. 54, ligne 20.

138. Taqyìd, p. 54, ligne 11.

139. GAS, vol. 1, p. 29.

140. Taqyì, p. 105.

141. GAS, vol. 1, p. 91.

142. 'Ilal, p. 348.

143. Tahdib, vol. 6, p. 358.

144. Tahdīib, vol. 4, p. 195 ; s. v. Sulaiman b. Mihrān al-A'māš.

145. Ibn Sa'd, vol. 5, p. 353. Voir § 11.

146. GAS, vol. 1, p. 86 .

147. Tahdïb, vol. 11, p. 59 .

148. GAS, vol. 1, p. 305 et suiv.

149. Mīzān, vol. 1, p. 653 ; Mağrūḥinn, vol. 1, p. 283.

150. Taqyìd, p. 65-68.

151. Mìzān, vol. 1, p. 653.

152. Taqyì, p. 68-70; diagramme III 2.

153. Taqyìd, p. 89-90.

154. Taqyìd, p. 92.

155. Taqyid, p. 96-97.

156. Taqyīd,p. 88 ; Ibn Abī Šaiba, vol. 9, p. 49, nº 6478.

157. Voir Goldziher, in : ZDMG 61 (1907), p. 869 et suiv.

158. In : Tahdīib, vol. 8, p. 47 et suiv., s. v. 'Amr b. Šu'aib ; Mīzān, vol. 3, p. 264 et suiv. ; Ibn Qutaiba, p. 93.

159. Cf. J. Fück, in : ZDMG 92 (1938), p. 62.

160. Cf. I. Goldziher, in : ZDMG 50 (1896), p. 466 et suiv. ; Fück, ibid., p. 62 et suiv.

161. Oxford, 1950, p. 171 et suiv.

162. Juynboll, p. 206 et suiv.

163. Șahịh, vol. 18, p. 129.

164. Sunan, vol. 3, p. $434, \mathrm{n}^{\circ} 3647$.

165. Șahih, vol. 2, p. 111.

166. Mizān, vol. 2, p. 564 et suiv.

167. Voir Fath, vol. 1, p. 315 ; Taqyìd, p. 32.

168. Vol. 3, p. 12 et suiv.

169. Cf. al-'Uš, Taqyīd, p. 34, note 21 .

170. Șahịh, vol. 2, p. 111.

171. Dārimī, vol. 1, p. 98.

172. Tahdiib, vol. 4, p. 104.

173. Ibn Sa'd, vol. 2/II, p. 117 ; Ibn Abī Šaiba, vol. 9, p. 53, nº 6497.

174. Mìzān, vol. 3, p. 404 et suiv.

175. Abū Haitama, p. 131, $\mathrm{n}^{\circ} 95$.

176. Ibn Abī Šaiba, vol. 9, p. 52, nº 6491.

177. Taqyīd, p. 93 ; Abū Dāwūd, vol. 3, p. 434, no 3648. Le tašahhud est la récitation de la šahāda (le témoignade de fois de l'islam), spécialement dans la șalāt (la prière).

178. Abū Huaitama, p. 145, $\mathrm{n}^{\circ} 153$.

179. Ibn Abī Šaiba, vol. 9, p. 53, $n^{\circ} 6495$.

180. Ibn Abī Šaiba, vol. 9, p. 49 et suiv., $n^{\circ} 6479$.

181. 'Abdarrazzāq, vol. 11, p. 259, nº 20489.

182. Abū Dāwūd, vol. 3, p. 434, nº 3646.

183. Fath, vol. 1, p. 313 et suiv.

184. Tirmidī, vol. 2, p. 111. 
185. Fath, vol. 1, p.311 et suiv. ; Abū Dāwūd, vol. 3, p. 434 ; Tirmidīi, vol. 2, p. 111.

186. Cf. Juynboll, The Authenticity, p. 49.

187. Ibn Abī Šaiba, vol. 9, p. 49, nº 6479 ; Abū Dāwūd, vol. 3, p. 434, nº 3646.

188. Tahdïb, vol. 9, p. 123.

189. Tahdib, vol. 7, p. 3.

190. Ibn Hibbān chez Ibn Ḥağar : Tahdīib, ibid.

191. Cf. H. Motzki, Quellenstudien zur Entstehung der islamischen Jurisprudenz: Die mekkanische Rechtsschule bis zur Mitte des 2./8. Jahrhunderts, thèse d'habilitation non publiée, Hambourg, 1988, p. 206.

192. 'Abdarrazzāq, vol. 11, p. 259, nº 20489.

193. Michael Cook : "The Opponents of the Writing of Tradition in Early Islam », Arabica 44, 1997, p. 437-530.

194. Cook (1997), p. 442.

195. Cook (1997), p. 448 ; cf. p. 490 sq.

196. Cook (1997), p. 491.

197. Cf. p. 141 [§107]; ad p. 139-140 [= § 113].

198. Voir p. 123-124 [= § 63-67]

199. Cook (1997), p. 474.

200. Mejr J. Kister : « Lā taqra' ù 'l-qurāna 'alā 'l-muṣhafiyyīn ... Some Notes on the Transmission of Ḥadìt », Jerusalem Studies in Arabic and Islam 22, 1998, p. 127-162.

201. Cf. Cook (1997), p. 460 sq.

202. Cook (1997), p. 461.

203. Cf. p. 124 [= § 64 et suiv.].

204. Cook (1997), p. 469.

205. Cook (1997), p. 470.

206. Cook (1997), p. 491.

INDEX

Schlüsselwörter : Thora, Ḥadīth, Überlieferung, Redaktion, Islamwissenschaft

Mots-clés : Torah, hadith, transmission, rédaction, études islamiques

\section{AUTEURS}

\section{GREGOR SCHOELER}

Gregor Schoeler est professeur émérite d'islamologie à l'Université de Bâle. Pour plus d'informations voir la notice suivante. 